\title{
Observational Evidence that Radiative Heating Modifies the Life Cycle of Tropical Anvil Clouds
}

\author{
CASEy J. WALl AND JOEl R. NORRIS \\ Scripps Institution of Oceanography, University of California, San Diego, La Jolla, California \\ BLAŽ GASPARINI \\ Department of Atmospheric Sciences, University of Washington, Seattle, Washington \\ WILLIAM L. SMITH JR. \\ NASA Langley Research Center, Hampton, Virginia \\ MANDANA M. THIEMAN \\ Science Systems and Applications, Inc., Hampton, Virginia \\ ODRAN SOURDEVAL \\ CNRS, UMR 8518-Laboratoire d'Optique Atmosphérique, University of Lille, Lille, France
}

(Manuscript received 22 March 2020, in final form 22 May 2020)

\begin{abstract}
A variety of satellite and ground-based observations are used to study how diurnal variations of cloud radiative heating affect the life cycle of anvil clouds over the tropical western Pacific Ocean. High clouds thicker than $2 \mathrm{~km}$ experience longwave heating at cloud base, longwave cooling at cloud top, and shortwave heating at cloud top. The shortwave and longwave effects have similar magnitudes during midday, but only the longwave effect is present at night, so high clouds experience a substantial diurnal cycle of radiative heating. Furthermore, anvil clouds are more persistent or laterally expansive during daytime. This cannot be explained by variations of convective intensity or geographic patterns of convection, suggesting that shortwave heating causes anvil clouds to persist longer or spread over a larger area. It is then investigated if shortwave heating modifies anvil development by altering turbulence in the cloud. According to one theory, radiative heating drives turbulent overturning within anvil clouds that can be sufficiently vigorous to cause ice nucleation in the updrafts, thereby extending the cloud lifetime. High-frequency air motion and ice-crystal number concentration are shown to be inversely related near cloud top, however. This suggests that turbulence depletes or disperses ice crystals at a faster rate than it nucleates them, so another mechanism must cause the diurnal variation of anvil clouds. It is hypothesized that radiative heating affects anvil development primarily by inducing a mesoscale circulation that offsets gravitational settling of cloud particles.
\end{abstract}

KEYWORDS: Convective clouds; Deep convection; Diurnal effects; Cloud microphysics; Cloud radiative effects; Mesoscale processes

\section{Introduction}

Deep convective cloud systems typically contain extensive upper-level anvil clouds that spread laterally from the convection. It has long been recognized that

¿ Denotes content that is immediately available upon publication as open access.

Corresponding author: Casey J. Wall, cawall@ucsd.edu these clouds are fundamental to the radiation budget and general circulation of the atmosphere, but understanding the complex interaction of processes within them has proven to be challenging (Houze 1982; Hartmann et al. 1984; Ramanathan et al. 1989). For instance, most of the ice in fresh anvil clouds occurs as crystals that are large enough to fall out of the upper troposphere within a few hours, yet anvils typically persist for much longer (Mace et al. 2006; Jensen et al. 2018). Some feedback processes must therefore exist to 
Microphysical Cycling Mechanism

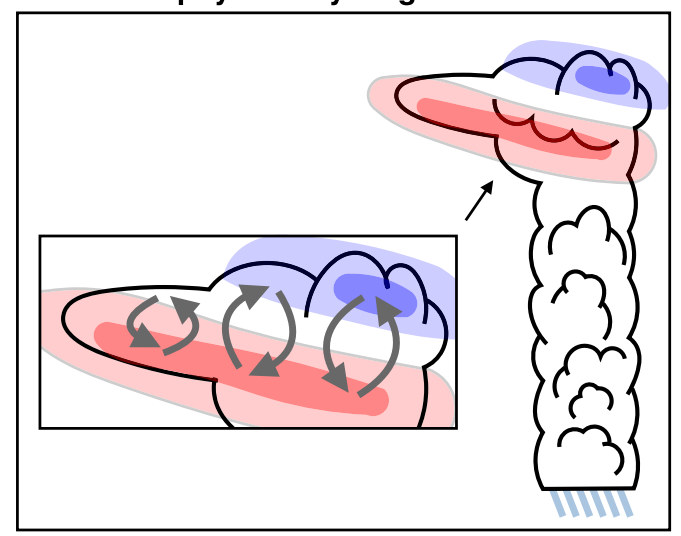

Anvil Lifting Mechanism

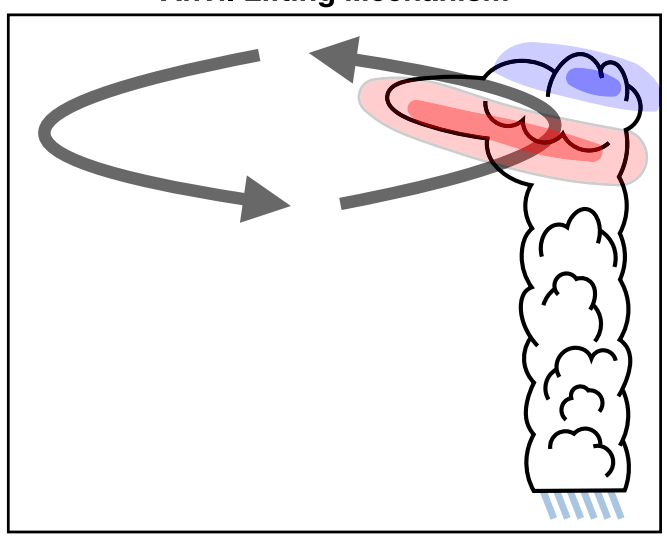

FIG. 1. Illustration of the proposed mechanisms of anvil-radiation interaction. Colors indicate typical radiative heating profiles in anvil clouds, and small and large gray arrows indicate turbulent and mesoscale circulations, respectively. (left) The microphysical cycling mechanism: Gradients of radiative heating within the cloud drive turbulence, which modulates microphysical processes. (right) The anvil lifting mechanism: Radiative heating of the anvil drives a mesoscale circulation that lifts and spreads the cloud. The radiative heating profile shown here is meant to represent a typical daily mean value, but the heating profile varies throughout the day.

extend the cloud lifetime. The feedbacks may involve radiative heating, latent heating, cloud microphysics, turbulence, or mesoscale circulations, but the links between these processes are not fully understood.

One process that has been suggested to affect anvil development is the interaction among radiative heating, microphysics, and circulation within the cloud. Numerous modeling studies have investigated this process, and they generally suggest that radiative heating acts to extend the lifetime of elevated ice clouds (Starr and Cox 1985; Fu et al. 1995; Tao et al. 1996; Dobbie and Jonas 2001; Durran et al. 2009; Dinh et al. 2010; Harrop and Hartmann 2016; Hartmann and Berry 2017; Hartmann et al. 2018; Gasparini et al. 2019). However, some studies suggest that radiative heating may have little influence on anvil clouds or that it accelerates cloud decay (Boehm et al. 1999; Seeley et al. 2019). It is difficult to rule out any of these possibilities because current models are very sensitive to the parameterization of ice microphysics (Feng et al. 2018; Hartmann et al. 2018; Wall and Hartmann 2018; Gasparini et al. 2019). Understanding how anvil clouds interact with radiation would therefore help to validate and improve the treatment of ice microphysics in numerical models.

Anvil-radiation interaction is also of interest because it is relevant to several theories on tropical climate. Hartmann et al. (2018) argued that radiative heating is critical to the life cycle of anvil clouds, and that it is responsible for the similarity of the radiation balance in convective and adjacent nonconvective regions of the tropics. In contrast, Seeley et al. (2019) argued that radiative heating may have little influence on the development of anvil clouds, and they used this statement to justify their theory on the existence of anvils. These studies make far-reaching predictions about fundamental aspects of tropical climate, yet they are based on conflicting statements about how radiation affects anvil cloud development. It is therefore important to better understand this process.

The mechanisms of anvil-radiation interaction that have been proposed can be broadly grouped into two categories. The first, which we call the "microphysical cycling mechanism," is illustrated in Fig. 1. This theory emphasizes the role of radiation in establishing heating gradients within clouds that destabilize the cloud layer (Starr and Cox 1985; Hartmann et al. 2018). This drives turbulent overturning within the cloud, which warms and cools air parcels as they circulate vertically. Ice crystals shrink by sublimation in the downdrafts and grow by vapor deposition in the updrafts, creating a cycle between vapor and ice. Hartmann et al. (2018) posited that the turbulence in anvils may be sufficiently vigorous to produce high supersaturation within the updrafts, causing fresh nucleation of ice crystals. Ice nucleation is a critical component of the mechanism because it greatly enhances the conversion of vapor to ice in the turbulent updrafts. By continuing to nucleate ice as the cloud evolves, the microphysical cycling mechanism extends the cloud lifetime.

While ice nucleation in aged anvil clouds can be important in numerical simulations, it is unclear how often it occurs in nature. Nucleation events have been observed at the boundaries of anvil clouds where the concentration of preexisting ice is small enough that it does not constrain supersaturation. For instance, Jensen 
et al. (2009) measured an anvil cloud that had regions with numerous small crystals at cloud top, which appeared to be caused by ice nucleation in turbulent updrafts or gravity waves. Gallagher et al. (2012) measured a predominance of small bullet-rosette crystals at the lateral edges of an anvil, indicating that the crystals grew in the upper troposphere and perhaps nucleated near the cloud edge. Other field studies suggest that ice nucleation may be rare within anvil clouds, however (Lawson et al. 2010, 2019). A key goal for evaluating the microphysical cycling theory is to determine how often fresh nucleation of ice crystals occurs within aged anvil cirrus.

The second proposed mechanism of anvil-radiation interaction, which we call the "anvil lifting mechanism," is also illustrated in Fig. 1. This theory emphasizes the effect of horizontal gradients of radiative heating between anvil clouds and the adjacent environment. The heating gradient drives a mesoscale circulation that lifts and spreads the cloud (Ackerman et al. 1988; Lilly 1988; Durran et al. 2009; Dinh et al. 2010; Schmidt and Garrett 2013). The mesoscale lifting is more gradual than the turbulent updrafts within the cloud, so it probably does not cause ice nucleation (Dinh et al. 2010). Rather, mesoscale lifting offsets the gravitational settling of cloud particles, which slows the sedimentation of the cloud into lower levels of the atmosphere where the ice crystals can sublimate. This extends the cloud lifetime. The circulation may also extend the cloud lifetime by transporting water vapor from the adjacent environment into the cloud, though this effect could be less important for anvils and more important for long-lived thin cirrus (Sherwood 1999; Dinh et al. 2010). Garrett et al. (2005) presented an observational case study that is consistent with the anvil lifting mechanism, but it is unclear if this case is representative of anvil clouds in general.

The aforementioned studies have demonstrated the need to better observe the rapidly evolving processes within tropical anvil clouds, particularly those that involve cloud radiative heating. In this study we work toward this goal. The main objective of this work is to use diurnal variations of cloud radiative heating to investigate the mechanisms of anvil-radiation interaction.

\section{Data}

We analyze observations from the warm-pool region of the tropical western Pacific Ocean, where anvil clouds are common. Observational data are derived from polarorbiting satellites in the A-Train constellation (Stephens et al. 2002), ground-based radar from the Atmospheric Radiation Measurement Program (Ackerman and Stokes
2003), and the Himawari-8 geostationary satellite (Bessho et al. 2016). The datasets and study region are described below.

\section{a. A-Train satellites}

Instantaneous cloud and radiation data are obtained from satellites in the A-Train constellation, including the Clouds and the Earth's Radiant Energy System (CERES) and Moderate Resolution Imaging Spectroradiometer (MODIS) instruments on board the Aqua satellite, the Cloud-Aerosol Lidar with Orthogonal Polarization instrument on board the Cloud-Aerosol Lidar and Infrared Pathfinder Satellite Observations (CALIPSO) satellite, and the Cloud Profiling Radar on board the CloudSat satellite. Coincident measurements from these sensors are used to derive two of the datasets that are analyzed in this study.

We analyze vertical profiles of cloud fraction and irradiance from the CALIPSO-CloudSat-CERES-MODIS (CCCM) Merged Product version RelB1 (CERES Science Team 2016; Kato et al. 2010b). Cloud fraction is determined directly from the radar and lidar backscatter, and irradiance is determined indirectly through radiative transfer calculations that incorporate the observed cloud profiles (Kato et al. 2011). We also use the irradiance profile to calculate the radiative heating rate. For a given layer of the atmosphere, the radiative heating rate is calculated as

$$
\left.\frac{d T}{d t}\right|_{\mathrm{rad}}=-\frac{d R}{d z} \delta z\left(\frac{c_{p} \delta p}{g}\right)^{-1},
$$

where $d T /\left.d t\right|_{\mathrm{rad}}$ is the radiative heating rate, $R$ is the shortwave or longwave irradiance, $c_{p}$ is the specific heat capacity of dry air at constant pressure, $g$ is gravity, $\delta z$ is the thickness of the layer, and $\delta p$ is the pressure difference across the layer. Data are averaged over the CERES footprints, which have a horizontal resolution of about $25 \mathrm{~km}$. The vertical resolution is $240 \mathrm{~m}$ in the free troposphere (Kato et al. 2010a).

We also use retrievals of ice-crystal number concentration from the radar-lidar (DARDAR)-Nice dataset, version 1.0 (Sourdeval 2019; Sourdeval et al. 2018). These data include estimates of the concentration of ice crystals with a maximum diameter greater than $5 \mu \mathrm{m}$, and they are derived from radar and lidar measurements from CloudSat and CALIPSO. Since radar and lidar preferentially detect large and small cloud particles, respectively, the data are most reliable when measurements from both sensors are available. This typically occurs where the visible optical depth below cloud top is about 0.4-3 (McGill et al. 2007; Winker et al. 2007). Furthermore, the uncertainty is large when the 
temperature is warmer than $-30^{\circ} \mathrm{C}$ because of the complexity of the particle size distribution at these temperatures and because of challenges associated with distinguishing liquid and ice particles in mixed-phase clouds (Sourdeval et al. 2018; Krämer et al. 2020, manuscript submitted to Atmos. Chem. Phys. Discuss.). We therefore analyze the data in which radar and lidar measurements are both available and the temperature is colder than $-30^{\circ} \mathrm{C}$. Under these conditions the uncertainty for ice-crystal number concentration is about $25 \%$ (Sourdeval et al. 2018). We also verified that noise in the lidar signal from background solar radiation does not affect the optical depth below cloud top at which the radar and lidar coverage overlap, so day and night measurements can be compared at this level. The data have horizontal resolution of $1.7 \mathrm{~km}$ and vertical resolution of $60 \mathrm{~m}$.

The main advantage of the A-Train data is that they combine measurements from multiple sensors to achieve accurate and detailed cloud retrievals. For example, the lidar on CALIPSO detects thin clouds with visible optical depth $(\tau)$ as low as 0.01 , but the lidar pulse fully attenuates when $\tau \approx 3$ (McGill et al. 2007; Winker et al. 2007). The radar on CloudSat senses deeper into thick clouds but misses thin clouds, so both instruments are necessary to measure the full cloud ensemble that is produced by deep convection (Berry and Mace 2014). The cloud profiles from CloudSat and CALIPSO also improve the accuracy of the irradiance calculations, as do the constraints on cloud properties from MODIS (Kato et al. 2011). Furthermore, CloudSat and CALIPSO provide complementary information for estimating icecrystal number concentration. Thus, the combination of sensors greatly enhances the cloud retrievals.

The main disadvantage of the A-Train data is the sampling limitations of the sensors. Since the radar and lidar on CloudSat and CALIPSO are nadir-staring instruments, and since the A-Train follows a sun-synchronous orbit, all of the measurements are made around 0130 and 1330 LT. Furthermore, the retrieval of irradiance profiles requires knowledge of cloud optical depth, which MODIS cannot accurately retrieve for optically thick clouds at night. Radiative heating rates are therefore only computed during daytime. Poor sampling of the diurnal cycle is a limitation of the A-Train data.

\section{b. Ground-based MMCR}

We also use observations from a ground-based millimeter-wavelength cloud radar (MMCR) located at the Atmospheric Radiation Measurement Program site in Manus, Papua New Guinea $\left(2^{\circ} \mathrm{S}, 147^{\circ} \mathrm{E}\right.$ ) (Ackerman and Stokes 2003). Doppler velocity measurements from the MMCR are used to retrieve high-frequency vertical air motion within elevated ice clouds (Kalesse 2013). The retrieval technique captures turbulence and gravity waves with periods of $30 \mathrm{~min}$ or less, but it does not provide information about air motion that evolves more slowly. Mesoscale circulations are therefore not represented in this dataset. The data have 10-s temporal resolution, 135-m vertical resolution, and an uncertainty of $0.15 \mathrm{~m} \mathrm{~s}^{-1}$ (Kalesse and Kollias 2013; Muhlbauer et al. 2014).

The main limitation of these data is that vertical air motion can only be retrieved for clouds that satisfy special conditions. To make a retrieval, the cloud base must be above $6 \mathrm{~km}$, the cloud layer must be colder than $-10^{\circ} \mathrm{C}$, and the cloud must be sufficiently far away from deep convection. Convective scenes are excluded by requiring that high-cloud layers have a base that is at least $0.5 \mathrm{~km}$ above all of the cloud layers below. Furthermore, the cloud must persist for a sufficiently long time. It is required that the 20-min-average hydrometeor fraction at a given height exceeds $80 \%$. The dataset therefore includes estimates of high-frequency vertical air motion within clouds that are sufficiently high, thick, persistent, and separated from deep convection. These conditions include aged anvil clouds.

\section{c. Himawari-8}

We also analyze retrievals from the Himawari-8 geostationary satellite, which we henceforth call Himawari (Bessho et al. 2016). The Himawari satellite carries a high-resolution imager that measures multispectral radiances. These measurements are used to retrieve cloud properties and broadband outgoing longwave radiation (OLR). Cloud properties are derived from modified versions of the MODIS algorithms (Minnis et al. 2008; Trepte et al. 2019; Minnis et al. 2020), and OLR is derived using a modified version of the algorithm of Doelling et al. (2016) (see Wall et al. 2018 for details). The data are provided by the Satellite Cloud and Radiative Property Retrieval System at NASA Langley Research Center and made available by the CERES project (CERES Science Team 2017a). We analyze cloud-top pressure, cloud visible optical depth, OLR, and the infrared channel brightness temperature $(11.2 \mu \mathrm{m})$. Pixel-level data are analyzed, which are sampled to $\sim 8$-km horizontal resolution and 1-h temporal resolution due to processing and storage limitations.

Since we primarily analyze the OLR data from Himawari, we estimate its uncertainty by comparing it with coincident OLR data from CERES. OLR data from Himawari are matched with data from the Edition 4 CERES Aqua and Terra Single Scanner Footprint (SSF) product (CERES Science Team 2017b) within a 15-min window using a method similar to that of Wall et al. (2018). This comparison is summarized in Table 1. Upper bounds 
TABLE 1. Uncertainty of the Himawari OLR data. Himawari data are compared with coincident measurements from CERES on board the Aqua and Terra satellites. The bias and root-mean-square deviation (RMSD) relative to CERES are shown. Uncertainties are shown for daytime data, nighttime data, and day and night data combined.

\begin{tabular}{|c|c|c|c|c|c|c|}
\hline & $\begin{array}{c}\text { Satellite } \\
\text { overpass time }\end{array}$ & $\begin{array}{c}\text { OLR } \\
\text { bias }\left(\mathrm{W} \mathrm{m}^{-2}\right)\end{array}$ & $\begin{array}{c}\text { OLR } \\
\text { bias (\%) }\end{array}$ & $\begin{array}{c}\text { OLR } \\
\operatorname{RMSD}\left(\mathrm{W} \mathrm{m}^{-2}\right)\end{array}$ & $\begin{array}{c}\text { OLR } \\
\text { RMSD (\%) }\end{array}$ & $\begin{array}{l}\text { Number of } \\
\text { observations }\end{array}$ \\
\hline OLR compared to & Day & 0.0 & 0.0 & 7.1 & 2.9 & 142452 \\
\hline \multirow{2}{*}{ CERES-Aqua } & Night & -0.4 & -0.2 & 7.3 & 3.0 & 159856 \\
\hline & Day + night & -0.2 & -0.1 & 7.2 & 2.9 & 302308 \\
\hline OLR compared to & Day & -0.5 & -0.2 & 7.1 & 2.8 & 159855 \\
\hline \multirow[t]{2}{*}{ CERES-Terra } & Night & -0.4 & -0.2 & 6.7 & 2.7 & 144239 \\
\hline & Day + night & -0.5 & -0.2 & 6.9 & 2.8 & 304094 \\
\hline
\end{tabular}

for the OLR bias and root-mean-square deviation relative to CERES are -0.5 and $7.3 \mathrm{~W} \mathrm{~m}^{-2}$, respectively. The uncertainty is also similar during day and night, so the OLR data from Himawari are suitable for studying the diurnal cycle.

Two additional datasets are used with the Himawari data. We use lightning occurrence data from the World Wide Lightning Location Network, which is a global network of ground-based sensors that detect lightning using low-frequency radio waves (Dowden et al. 2002; Virts et al. 2013). Individual lightning strokes are located within an uncertainty of $5 \mathrm{~km}$ and $10 \mu \mathrm{s}$ (Abarca et al. 2010; Hutchins et al. 2012). The network has a global detection efficiency of $\sim 10 \%$ of all strokes, which is large enough to detect almost all lightning-producing storms (Jacobson et al. 2006; Rodger et al. 2006). We also analyze horizontal winds at $200 \mathrm{hPa}$ from the European Centre for Medium-Range Weather Forecasts reanalysis (Dee et al. 2011; ECMWF 2019). This dataset includes instantaneous wind fields every $6 \mathrm{~h}$ with $0.25^{\circ} \times 0.25^{\circ}$ horizontal resolution.

\section{d. Study domain}

Data are analyzed from the warm pool of the tropical western Pacific Ocean, as shown in Fig. 2. A-Train data are selected from $12^{\circ} \mathrm{S}$ to $12^{\circ} \mathrm{N}$ and from $145^{\circ}$ to $170^{\circ} \mathrm{E}$, and Himawari data are selected from a larger region that spans $20^{\circ} \mathrm{S}-20^{\circ} \mathrm{N}, 130^{\circ} \mathrm{E}-180^{\circ}$ to allow for analysis of cloud trajectories. These regions include the MMCR site. We analyze data from June, July, and August over the full records of CCCM, MMCR, and Himawari that were available at the time of study. This includes A-Train data from July 2006 through August 2010, MMCR data from July 1999 through August 2010, and Himawari data from July 2015 through August 2016. We only consider data over the ocean, except in the case of the MMCR, which is located on a small island. This restriction is made to avoid complications associated with the strong diurnal cycle of convective intensity that occurs over land (Nesbitt and Zipser 2003).

\section{Methods}

\section{a. Cloud-tracking algorithm}

A cloud-tracking algorithm is used to investigate the life cycle of anvil clouds. The algorithm is applied to infrared brightness temperature data from Himawari. These data occupy a three-dimensional space-time grid, and pixels within the grid are considered to be neighbors if they share a face or an edge (i.e., if they belong to an 18connected neighborhood of one another). The algorithm starts by identifying deep convection, as illustrated in Fig. 3. Convective "cold cores" are defined as connected groups of neighboring pixels that have brightness temperatures colder than $200 \mathrm{~K}$. Temperatures below this threshold account for the coldest $0.4 \%$ of the measurements, and when they occur over tropical oceans, they are always associated with deep convection. To be considered a cold core, the $200-\mathrm{K}$ cloud shield must contain at least 35 pixels and span at least $2 \mathrm{~h}$. This criterion is used to remove isolated cumulus so that only mesoscale convective systems are analyzed (Fiolleau and

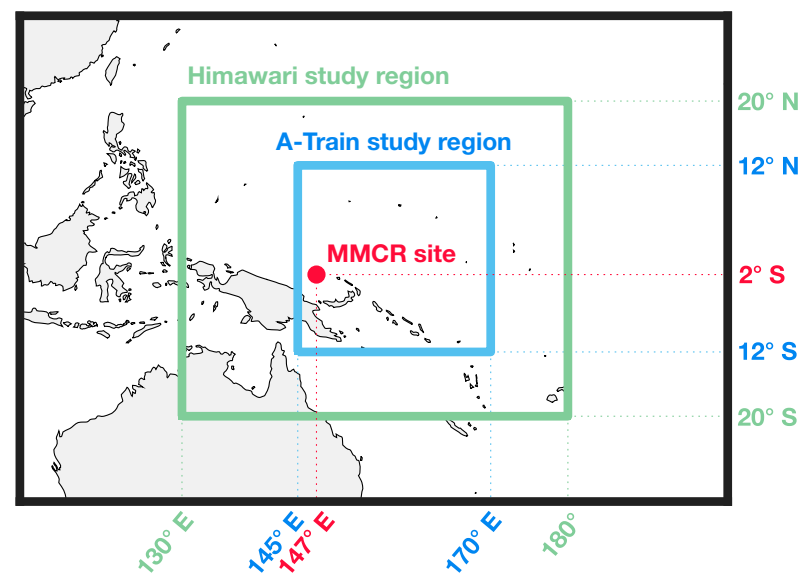

FIG. 2. Map of the study region. The boxes show the study regions for the Himawari and A-Train data, and the red circle shows the MMCR site. 
Time $\rightarrow$
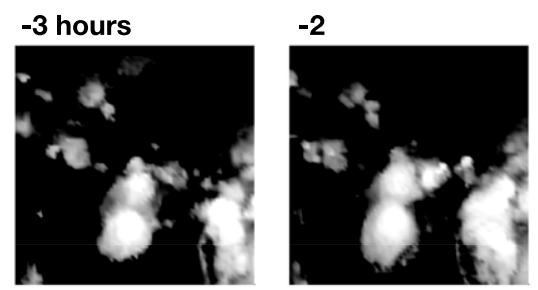

$-1$
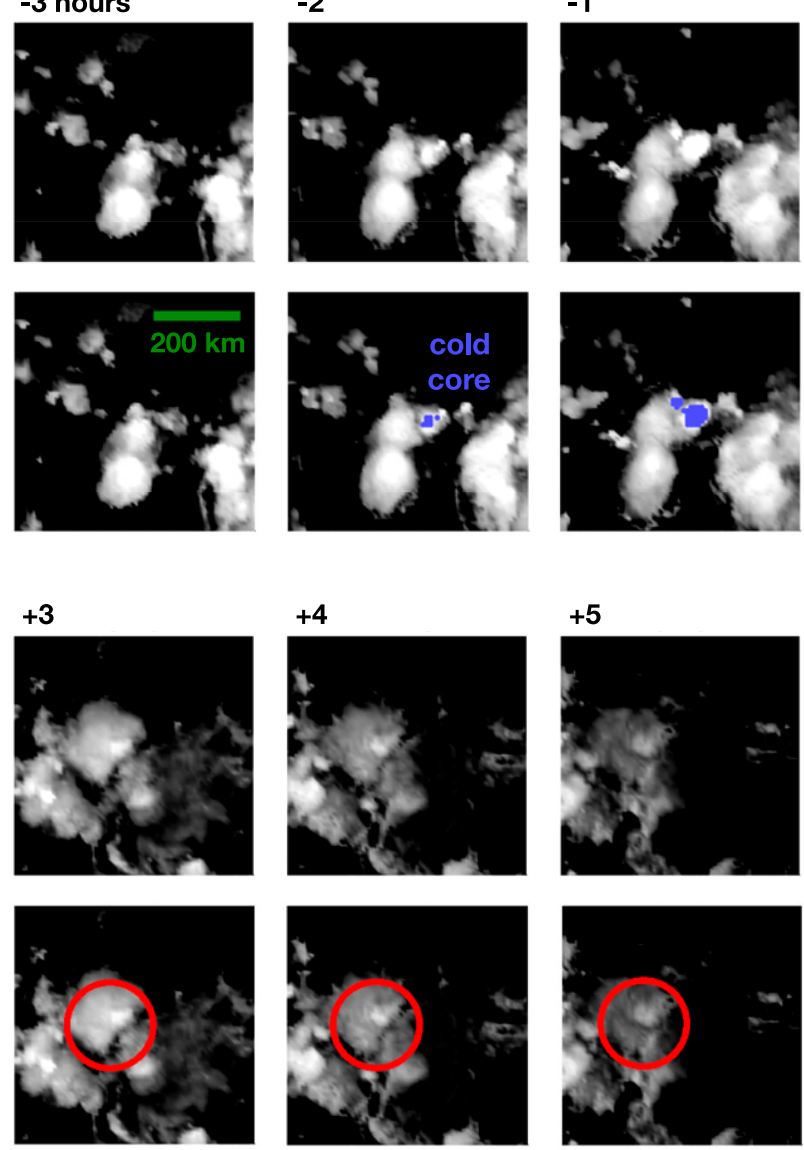

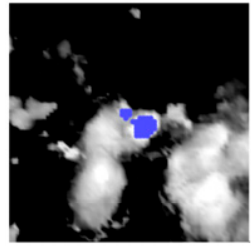

$+5$
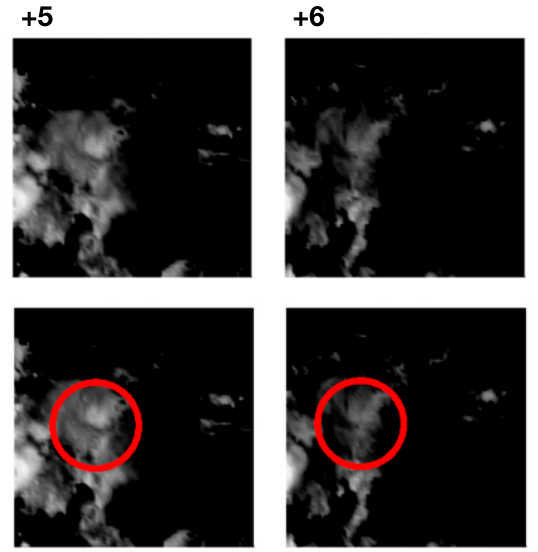
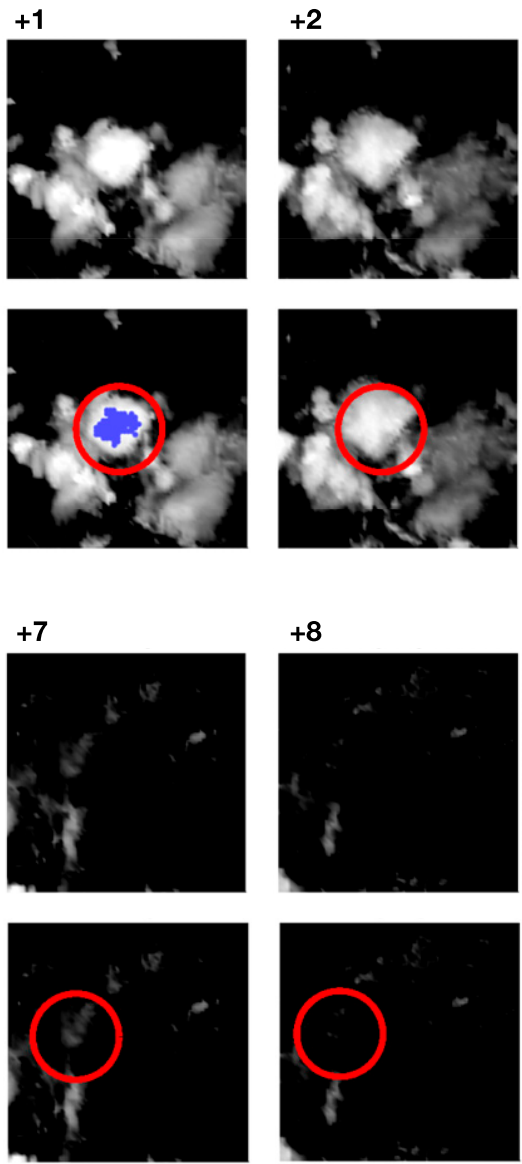

$+8$
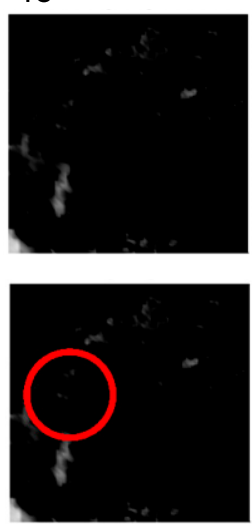

IR Brightness Temperature (K)

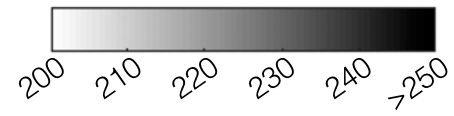

FIG. 3. Example of the cloud-tracking algorithm. (top row),(third row) A sequence of infrared images with the relative time in hours indicated above. (second row),(bottom row) Similar to the top and third rows, but marked to illustrate the cloud-tracking algorithm. An example cold core is shown in blue shading. The cold-core peak is defined as the time at which the cold core reaches its maximum area. The red circle shows the associated anvil region. The algorithm detects multiple cloud objects in this scene, but only one is shown for clarity. The frames are centered on $4^{\circ} \mathrm{S}, 150^{\circ} \mathrm{E}$, and the first frame was measured at 1030 UTC 24 Jun 2016. Data are from Himawari.

Roca 2013; Wall et al. 2018). Of all pixels colder than $200 \mathrm{~K}, 91 \%$ meet this criterion. The $200-\mathrm{K}$ cloud shield is also required to occur over the ocean, and it must be located at least 50 pixels horizontally $(\sim 400 \mathrm{~km})$ from the edge of the study domain.

The algorithm then identifies the anvil cloud associated with the convection. This is also illustrated in Fig. 3. First, the "cold-core peak" is defined as the time at which the cold core reaches its maximum area. At this time, the centroid position of the cold core is calculated. The anvil region is then defined by a circle centered on this point with a radius of $100 \mathrm{~km}$, which is the typical size of individual anvil clouds (Pope et al.
2008; Igel et al. 2014). The size of the anvil region is held constant, but we found similar results when varying it in proportion to the maximum area of the cold core. Then, as time advances, the anvil region is advected following the large-scale winds at $200 \mathrm{hPa}$ from reanalysis. The cloud trajectory is tracked for $12 \mathrm{~h}$, and data from within the anvil region are composited as a function of time lag relative to the cold-core peak.

Conditional sampling is then applied to the cloud objects based on their trajectories. If the trajectory passes over land or leaves the study domain, then the associated pixels are excluded. Furthermore, if two trajectories converge and 
cause the cloud objects to overlap, then the overlapping pixels are assigned to both clouds. We tested if these conditions affect the results by performing the analysis on all of the cloud objects, on the cases where the cloud trajectories remain entirely within the study domain, and on the cases of isolated convection where the cloud objects do not overlap. The main results are the same in all cases.

This method of tracking anvil clouds differs from previous studies because it estimates the anvil domain as a circular region. Anvils are never perfectly circular, so this approximation introduces noise (Senf et al. 2018). However, our method has the advantage of detecting optically thick and thin portions of anvil clouds with equal fidelity, so it provides a noisy but unbiased perspective of the anvil life cycle. The noise can be dampened with a large sample size, leaving an unbiased view of the evolution from thick to thin anvil cloud.

\section{b. Identifying high-cloud layers in radar-lidar data}

We also use radar and lidar data to identify high-cloud layers. A binary cloud mask is first derived from each radar-lidar profile. The cloud-mask definition is kept as similar as possible between the three radar-lidar datasets, but some differences are unavoidable. In the case of the MMCR, the cloud mask is defined based on the range bins in which in-cloud vertical air motion is retrieved. In the case of CCCM, the default cloud profile has $25-\mathrm{km}$ horizontal resolution, so the cloud mask is defined by assigning a value of 1 to the range bins in which the $25-\mathrm{km}$-average cloud fraction exceeds $50 \%$ and a value of 0 otherwise. In the case of DARDARNice, a cloud mask with horizontal resolution of $1.7 \mathrm{~km}$ is included, but we adjust the default cloud mask to account for the fact that the lidar on CALIPSO detects cloud layers with very low ice concentration more efficiently at night. Cloudy range bins that are detected by lidar only are treated as clear sky if the ice water content is below $2 \times 10^{-6} \mathrm{~kg} \mathrm{~m}^{-3}$, which is about the smallest value that can be detected during daytime (see appendix B). This adjustment is not made to the CCCM cloud mask because the necessary variables are not available, but we do not expect this to influence the results because we only use daytime measurements from CCCM. Differences in the cloud mask between the datasets will occur because of differences in the cloud-mask definition, instrument sensitivity, viewing geometry, and resolution, but the relative thickness of cloud layers can be used to compare the different observations. After the cloud mask is derived, it is scanned vertically to identify connected cloud layers with tops above $7 \mathrm{~km}$. Data are composited based on height relative to the top of the cloud layer.

Multilayer clouds complicate the analysis because radiative heating and microphysical properties of high clouds are affected by the presence of other cloud layers. For instance, tropopause cirrus may affect radiative heating within anvil clouds below (Garrett et al. 2006), and ice crystals that fall out of one cloud can seed lower cloud layers. In this study we only consider the cases in which one cloud layer with a top above $7 \mathrm{~km}$ is observed. These cases are detected in $17 \%, 32 \%$, and $51 \%$ of the measurements in the MMCR, DARDAR-Nice, and CCCM datasets, respectively. It is useful to study these cases because the proposed mechanisms of anvil-radiation interaction were developed from models of single high-cloud layers.

\section{c. Estimating confidence intervals}

The cloud-tracking and cloud-layer data are used to compare high clouds that occur during day and during night. Confidence intervals are estimated to test if the day-night difference is statistically significant. In the case of the tracking analysis, the confidence interval for the mean computed over multiple cloud objects is estimated from the standard error:

$$
\mathrm{SE}=\frac{\sigma}{\sqrt{N \alpha}},
$$

where SE is the standard error of the mean, $\sigma$ is the standard deviation, $N$ is the number of cloud objects, and $\alpha$ adjusts the sample size to account for the fact that the cloud objects sometimes overlap. The quantity $\alpha$ is defined as the number of unique pixels in the composite divided by the total number of pixels in the composite. The $95 \%$ confidence interval for the mean is \pm 1.96 SE.

Confidence intervals for other statistics are estimated by bootstrapping. For the tracking analysis, cloud objects are randomly selected with replacement to generate 1000 bootstrap samples of the distribution. The $95 \%$ confidence interval for a statistic $X$ is determined by the 2.5 th and 97.5th percentiles of $X$ calculated from the bootstrap samples. A similar procedure is used for the cloud-layer analysis; but in that case, bootstrapping is applied to segments of data to account for serial correlation between adjacent measurements. For the A-Train data, the satellite return period is much longer than the convective life cycle, so bootstrapping is applied to segments of data associated with individual satellite overpasses. For the MMCR data, the longest gravity wave period that is resolved is $30 \mathrm{~min}$, so bootstrapping is applied to 30 -min intervals.

\section{Results}

\section{a. Diurnal variation of the life cycle of anvil clouds}

The main objective of this study is to use diurnal variations of cloud radiative heating to investigate the mechanisms of anvil-radiation interaction. To start, let 


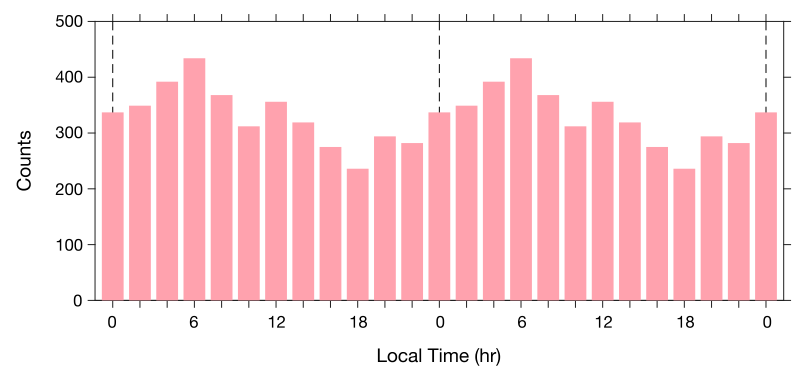

FIG. 4. The diurnal cycle of deep convection. The histogram shows the local solar time of the cold-core peak identified by the cloud-tracking method. The bin width is $2 \mathrm{~h}$ and the bin center is indicated on the horizontal axis. The diurnal cycle is plotted twice for clarity. Data are from Himawari.

us review the diurnal cycle of convection over the tropical western Pacific Ocean. The diurnal cycle of convection is illustrated in Fig. 4 using the time of day that clouds are detected by the tracking method. The histogram in this figure shows the local solar time of the cold-core peak, which indicates the approximate time of peak convective activity. Here we see the wellestablished result that deep convection occurs most often during the predawn and early morning hours (Gray and Jacobson 1977; Chen and Houze 1997; Nesbitt and Zipser 2003). Several mechanisms have been proposed to explain this cycle. One possibility is that solar heating warms the troposphere during the day and causes a sufficient reduction of environmental relative humidity to disfavor convection then (Tao et al. 1996; Dai 2001). The daytime warming is concentrated in the upper troposphere because of shortwave absorption in high clouds, so shortwave radiation may also inhibit convection by stabilizing the atmosphere (Kraus 1963; Randall et al. 1991). Shortwave radiation also reduces the contrast of atmospheric radiative cooling between convective and adjacent nonconvective regions, which may weaken the large-scale overturning motions that connect them and further modulate the convection (Gray and Jacobson 1977). The diurnal cycle of insolation may also modify the upper ocean and excite convectively coupled equatorial waves (Chen and Houze 1997). The relative importance of these mechanisms is under debate, but the fact that convection has a diurnal cycle is evidence of the dynamic nature of the tropical warm pool.

Since shortwave absorption in high clouds is thought to affect large-scale diurnal circulation adjustments, it seems worth considering whether it also affects circulations on the mesoscale and smaller (Ciesielski et al. 2018; Ruppert and Klocke 2019). The potential importance of solar heating for the circulation within high clouds can be seen in Fig. 5, which shows the radiative heating rate at $1330 \mathrm{LT}$ in cloud layers with tops above $7 \mathrm{~km}$. This figure is generated from data that are horizontally averaged over $25-\mathrm{km}$ segments, so finescale features of the heating profile may be smoothed out. Figure 5 therefore represents the general structure of (a) SW Heating

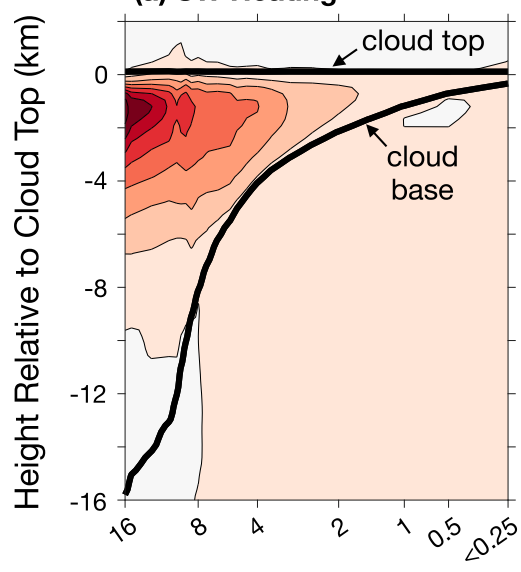

(b) LW Heating

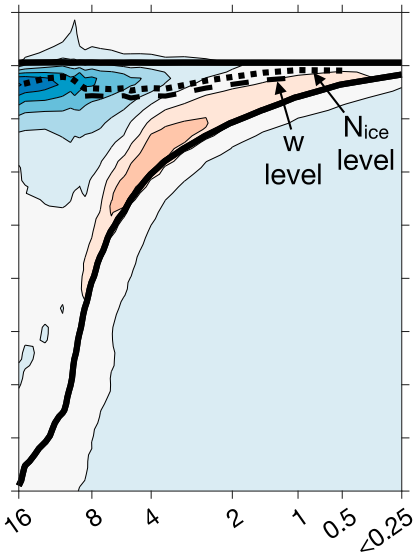

(c) Net Heating

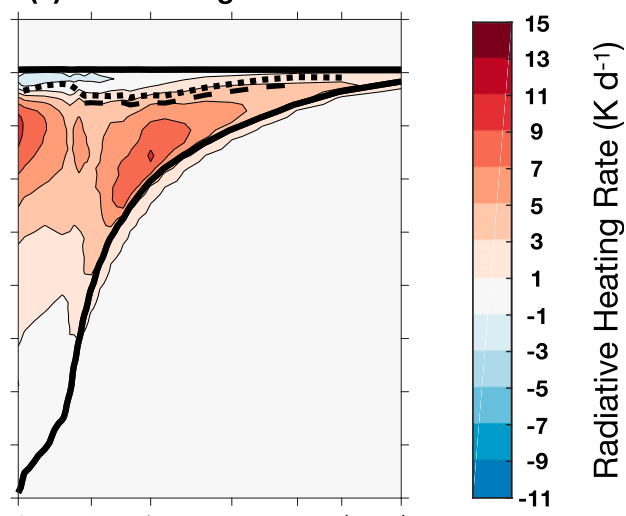

High-Cloud Thickness (km)

FIG. 5. Radiative heating rates at 1330 LT within cloud layers that have tops above $7 \mathrm{~km}$. (a) Shortwave (SW), (b) longwave (LW), and (c) net radiative heating rates are plotted as a function of cloud geometric thickness and height relative to cloud top. The horizontal axis is scaled by the number of observations in each cloud-thickness bin. The thick black lines show the cloud top and cloud base. The $w$ level line shows an estimate of the highest level in the cloud where vertical air motion data are available, and the length of this line indicates the range of cloud thicknesses for which air motion data are available (see appendix A). The $N_{\text {ice }}$ level line shows the average level from which ice-crystal number concentration data are selected. The $w$ level and $N_{\text {ice }}$ level correspond to the height of the data plotted in Figs. 11 and 12, respectively. Data are from the A-Train satellites (CCCM). 

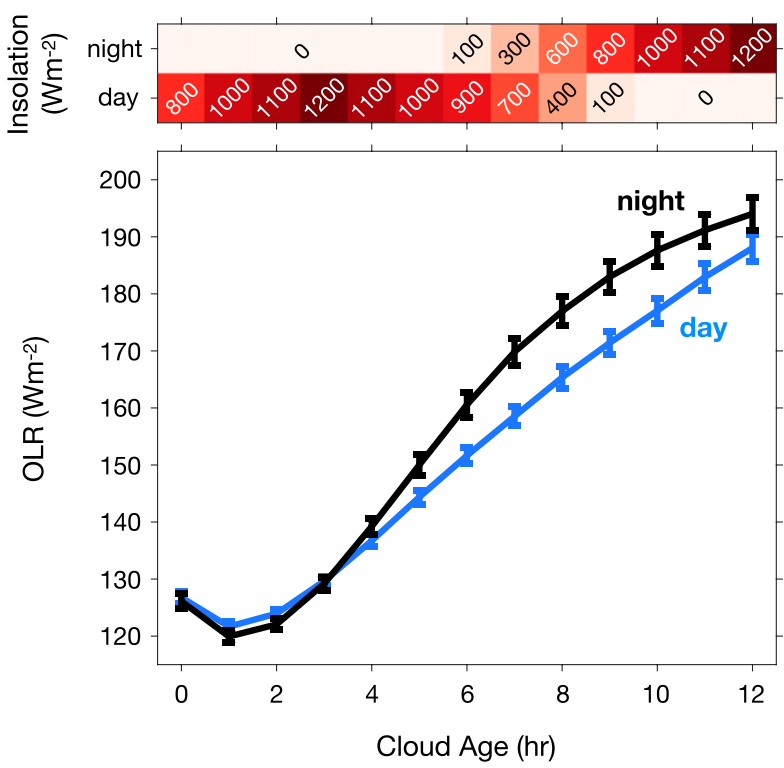

FIG. 6. Diurnal variation of the life cycle of anvil clouds. Cloud objects identified by the tracking algorithm are sorted into a day and a night composite in which the cold-core peak occurs between 0600 and 1200 LT and between 2100 and 0300 LT, respectively. Insolation and OLR averaged over the anvil region are plotted as a function of cloud age. A cloud age of zero corresponds to the coldcore peak. Error bars show the $95 \%$ confidence interval for the mean. Data are from Himawari.

radiative heating over spatial scales comparable to the size of the cloud. In this figure the clouds that are thicker than $10 \mathrm{~km}$ typically correspond to convective cores and precipitating anvils, and the thinner clouds correspond to nonprecipitating anvils and thin cirrus (Yuan and Houze 2010). Longwave radiation preferentially heats the base of all cloud layers and cools the top of clouds that are thicker than $2 \mathrm{~km}$, so it acts to destabilize high-cloud layers. This effect has been emphasized in previous studies because the magnitude of longwave heating and cooling exceeds the magnitude of shortwave heating in the daily mean. What is perhaps less appreciated, however, is that shortwave heating is substantial during midday and even exceeds the magnitude of longwave heating and cooling in many parts of high clouds. The shortwave heating rate is everywhere positive, and it preferentially heats the cloud top, counteracting the destabilizing effect of longwave radiation in all but the top $1 \mathrm{~km}$ of the cloud. If we assume that the longwave cloud-heating profile at $1330 \mathrm{LT}$ is similar to the longwave profile that occurs at night, then the diurnal variation of the net radiative heating of high clouds can be estimated by comparing Figs. $5 \mathrm{~b}$ and $5 \mathrm{c}$. This comparison suggests that radiative heating of anvil clouds varies substantially throughout the day.
The diurnal variation of cloud radiative heating motivates an investigation of whether anvil clouds develop differently based on the time of day that they occur. Shortwave radiation heats the cloud, so it is expected to invigorate the anvil lifting mechanism. Shortwave radiation also stabilizes the vertical heating gradient in all but the top $1 \mathrm{~km}$ of high clouds. If this stabilizing effect dampens turbulent overturning in anvil clouds, then it could weaken the microphysical cycling mechanism as well. Thus, we might expect to see evidence of these mechanisms in the diurnal variation of the anvil life cycle.

We investigate diurnal variations of the anvil life cycle using the cloud-tracking method. Cloud objects are sorted into a day and a night composite that correspond to the cases in which the local solar time of the cold-core peak occurs between 0600 and 1200 LT and 2100 and 0300 LT, respectively. The day composite includes morning convection because anvil clouds typically mature several hours after the peak of convective activity (Chen and Houze 1997). This means that anvil clouds in the day composite will typically mature during midday, when solar heating is strongest. The day and night composites contain 1109 and 968 cloud objects, respectively.

Figure 6 shows the composite life cycle of anvil clouds for the day and night cases. Anvil development is indicated by the cloud age, which is defined as the time lag relative to the cold-core peak. The top of the figure shows insolation averaged over the anvil region. In the day case, insolation is initially $800 \mathrm{~W} \mathrm{~m}^{-2}$ and increases to its maximum value when the cloud age is $3 \mathrm{~h}$. Insolation then steadily decreases until the sun sets, at which point the cloud age is approximately $10 \mathrm{~h}$. For the night case, insolation is near zero for the first $6 \mathrm{~h}$ and then steadily increases as the sun rises. The evolution of OLR averaged over the anvil region is also included to show the typical cloud life cycle. In both cases OLR decreases over the first hour as the anvil rapidly spreads from its parent convection (Fig. 3). OLR then increases with time as the anvil ages and thins. The rate of increase of OLR is significantly slower during daytime, indicating that anvils persist longer or spread over a larger area then.

The life cycle of anvil clouds is shown in more detail in Fig. 7. This figure shows the evolution of the OLR distribution within the anvil region. To help interpret the OLR distribution, Fig. 7e shows the interquartile range of OLR for pixels that have cloud-top pressure less than $440 \mathrm{hPa}$ and that correspond to optically thick $(\tau \geq 23)$, intermediate $(3.6 \leq \tau<23)$, and thin $(\tau<3.6)$ clouds. These values are computed from daytime data because $\tau$ is not derived for optically thick clouds at night, but we expect the $\tau$-OLR relationship to be similar at night. Using these values as a guide, the life cycle of anvil 


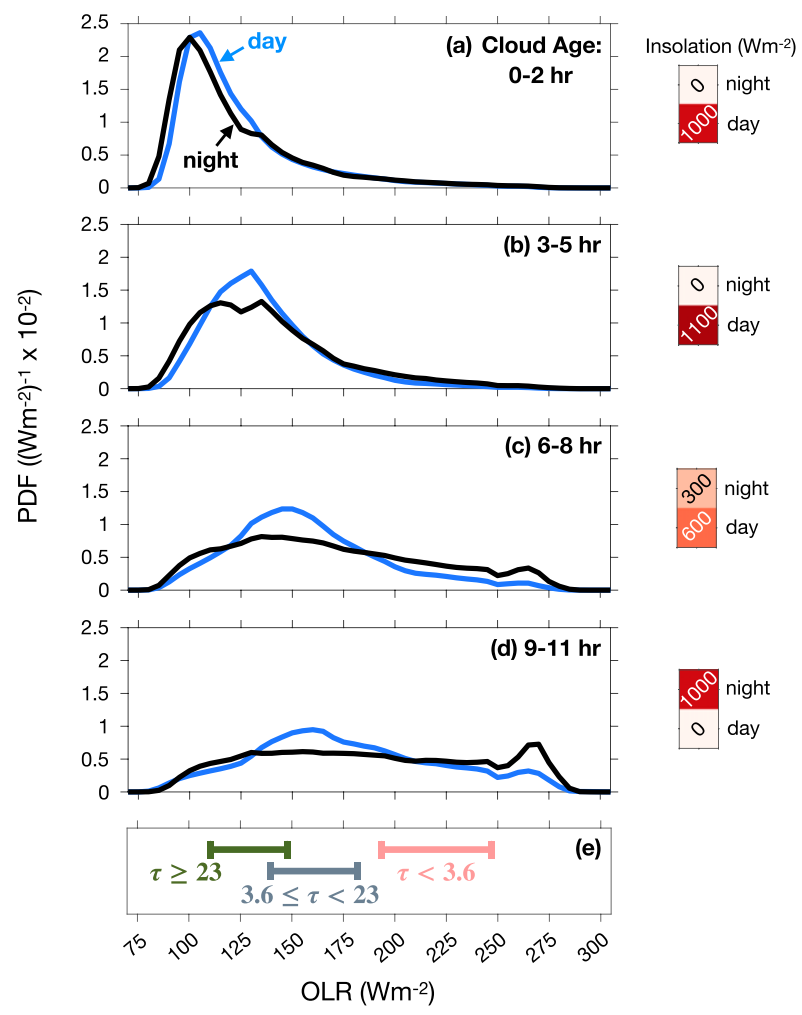

FIG. 7. (left) Evolution of the OLR distribution over the anvil life cycle. As in Fig. 6, anvil cloud objects from the day and night composites are shown separately. (a)-(d) The probability density function (PDF) of OLR for different values of cloud age. A cloud age of zero corresponds to the cold-core peak. (e) The interquartile range of OLR for pixels with cloud-top pressure less than $440 \mathrm{hPa}$ and visible optical depth $(\tau)$ within the intervals indicated on the plot. (right) The mean insolation. Data are from Himawari.

clouds can be seen in Figs. 7a-d. When the cloud age is $0-2 \mathrm{~h}$, the OLR distribution peaks around values of $100 \mathrm{~W} \mathrm{~m}^{-2}$, which corresponds to cumulonimbus and optically thick anvil. As the cloud develops further through its life cycle, OLR values in the range of $125-175 \mathrm{~W} \mathrm{~m}^{-2}$ persist longer in the day composite. These values correspond to optically thick and intermediate anvil cloud. In the night case, the OLR distribution shifts more rapidly to values above $200 \mathrm{~W} \mathrm{~m}^{-2}$, which correspond to thin cirrus. When the cloud age is 9-11 h, a second mode appears in the OLR distribution with values around $250-275 \mathrm{~W} \mathrm{~m}^{-2}$ (Fig. $7 \mathrm{~d}$ ). This mode corresponds to pixels that do not contain high clouds. The difference in this mode between the day and night cases indicates that aged anvil clouds cover a larger portion of the composite region in the day case. Thus, anvil clouds evolve differently during day and night. Optically thick and intermediate anvil cloud is more persistent, more laterally expansive, or both when the cloud is heated by the sun.

This finding is consistent with the idea that cloud radiative heating affects the anvil life cycle, but one may ask if

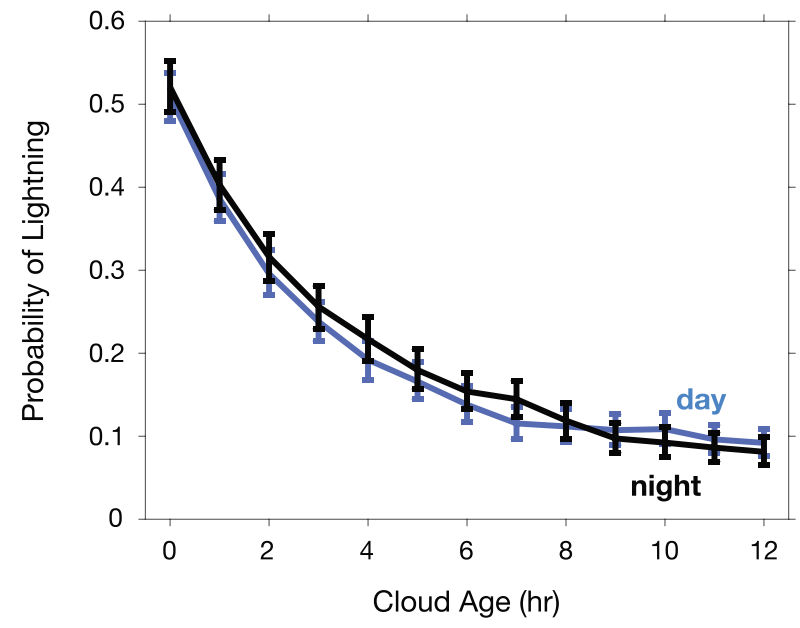

FIG. 8. Probability of lightning occurring within the anvil region plotted as a function of cloud age. A cloud age of zero corresponds to the cold-core peak. As in Figs. 6 and 7, anvil cloud objects from the day and night composites are shown separately. Lightning data are from the World Wide Lightning Location Network.

other confounding factors might explain the observations. For instance, if convective intensity were to vary throughout the day, then it could affect the initial properties of anvil clouds, which could then affect subsequent cloud development. To investigate this possibility, we use observations of lightning occurrence as a proxy for convective intensity. The anvil cloud trajectories are matched with lightning data to determine the probability of lightning occurring within the anvil region over 1 -h intervals. The result of this calculation is shown in Fig. 8. As expected, lightning is most common at the time of the cold-core peak and becomes less common as the cloud ages. Furthermore, the lightning probability is statistically indistinguishable between the day and night cases, meaning that the intensity of convection over the ocean does not vary systematically throughout the day. This is consistent with the findings of Nesbitt and Zipser (2003), who hypothesize that large-scale diurnal circulation adjustments can make the environment more or less favorable for the occurrence of convection, but they do not affect the intensity of convection when it does occur. Thus, convective-intensity variations cannot explain the diurnal variation of the anvil life cycle.

Another possible confounding factor could occur if the geographic distribution of anvil clouds is different between day and night. If so, the clouds in the day and night composites could systematically occur in different environmental conditions. This possibility is investigated in Fig. 9, which shows the locations of the cold cores. The geographic patterns of cold-core occurrences are similar for the day and night composites, so geography cannot explain the diurnal variation of the anvil life cycle either.

A further possibility is that diurnal variations of environmental humidity could affect anvil clouds. Free-tropospheric 

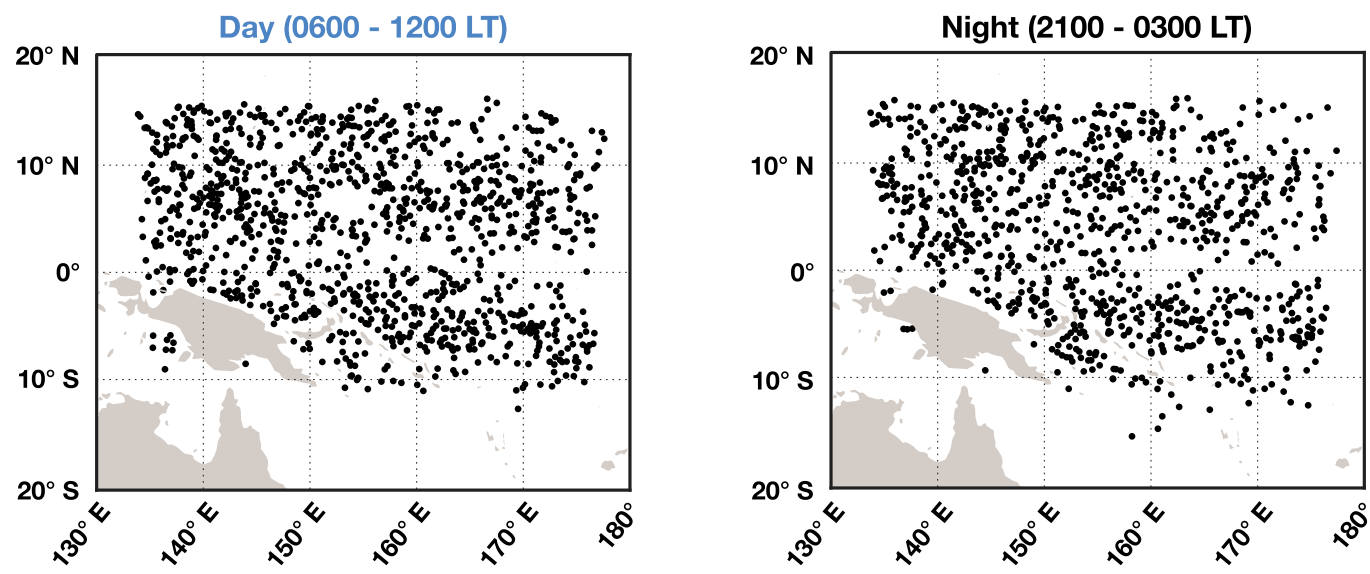

FIG. 9. Locations of the cold cores. Each point shows the center of one cold core at the time that it reaches its maximum area. The maps show the day and night cases, in which the cold-core peak occurs between 0600 and 1200 LT and between 2100 and 0300 LT, respectively. Data are from Himawari.

relative humidity has a diurnal cycle that maximizes at night over the tropical oceans (Chepfer et al. 2019). Higher relative humidity may reduce the effect of entrainment into convective plumes, allowing convective air parcels to maintain their buoyancy longer as they rise and therefore to produce deeper convective towers. Indeed, Fig. 7a shows that the lowest OLR values associated with deep convection are smaller at night, suggesting that the tops of deep convective clouds reach colder temperatures then. Since colder air is associated with lower saturation specific humidity, the primary effect of colder environmental temperature is to prolong the anvil lifetime by reducing the amount of sublimation that occurs when the cloud mixes with environmental air (Seeley et al. 2019). Diurnal variations of humidity may influence anvil development, but they probably act to extend the anvil lifetime at night, which is opposite to what is observed. Thus, this mechanism is also not the explanation for the daytime enhancement of anvil persistence or spreading that is seen in Figs. 6 and 7.

These findings indicate that the life cycle of tropical anvil clouds has a significant diurnal variation that cannot be explained by variations of convective intensity, geographic patterns of convection, or environmental humidity. This suggests that variations of cloud radiative heating cause the diurnal variation of the anvil life cycle.

\section{b. Investigating the microphysical cycling mechanism}

The results presented in the previous section show that solar radiation preferentially heats the top of high clouds that are thicker than $2 \mathrm{~km}$, and it stabilizes the vertical heating gradient in all but the top $1 \mathrm{~km}$ of these clouds (Fig. 5). The stabilization of the cloud may dampen the microphysical cycling mechanism and, thereby, act to reduce the anvil lifetime. However, anvil clouds are more persistent or laterally expansive when they are heated by the sun, suggesting that the microphysical cycling mechanism may not be the dominant process by which radiative heating affects anvil development. We will now investigate this idea more directly.

The effects of diurnal variations of radiative heating on the turbulence in high clouds is investigated using high-frequency vertical air motion retrieved by the MMCR, which represents turbulence and gravity waves with periods of $30 \mathrm{~min}$ or less. Several aspects of the data are important for their interpretation. First, data are only available for a limited subset of high clouds (section 2b). The line labeled " $w$ level" in Fig. 5 shows an estimate of the highest level in the cloud where vertical air motion is typically retrieved (see appendix A). This line also demonstrates the range of conditions for which vertical motion data are available. Data are not available for clouds thicker than $\sim 8 \mathrm{~km}$, and they are typically not available in the layer that is $0-1 \mathrm{~km}$ below the cloud top that would be reported by the A-Train satellites. Furthermore, data are only available for clouds that are detected by radar, so the cloud must contain some relatively large ice particles. This means that anvil clouds are typically detected, but thin cirrus are often undetected (Berry and Mace 2014). Thus, the results presented hereinafter represent air motion in aged anvil clouds.

To investigate the diurnal variation of in-cloud air motion we composite the data based on time of day, cloud geometric thickness, and height relative to cloud top. Day and night composites are generated from the measurements with local solar time between 0900 and 1500 LT and 2100 and 0300 LT, respectively. Here the 
Thick Clouds
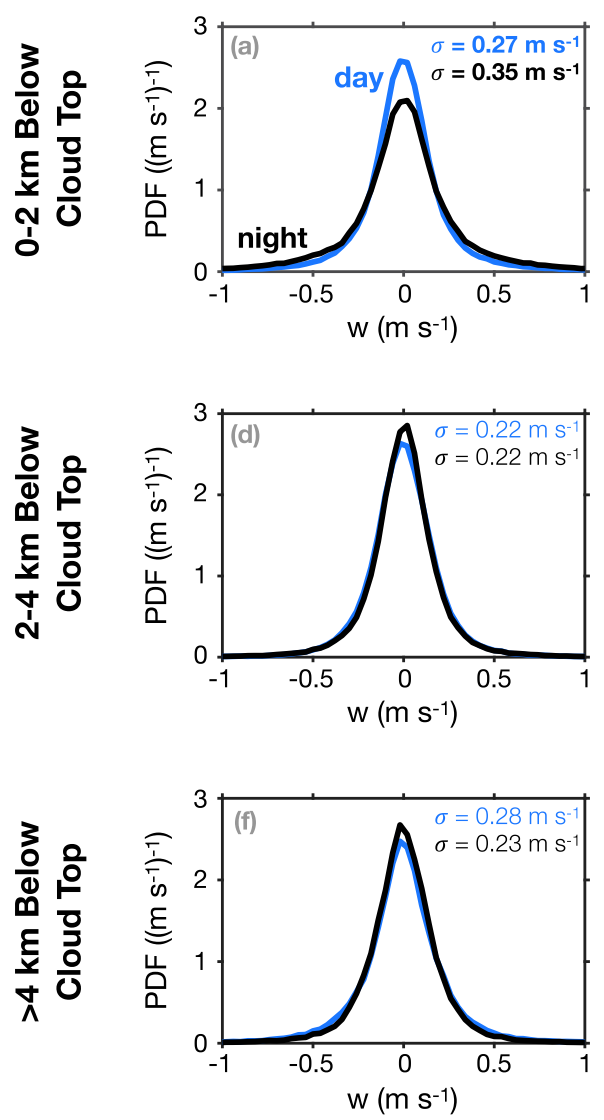

Medium Clouds
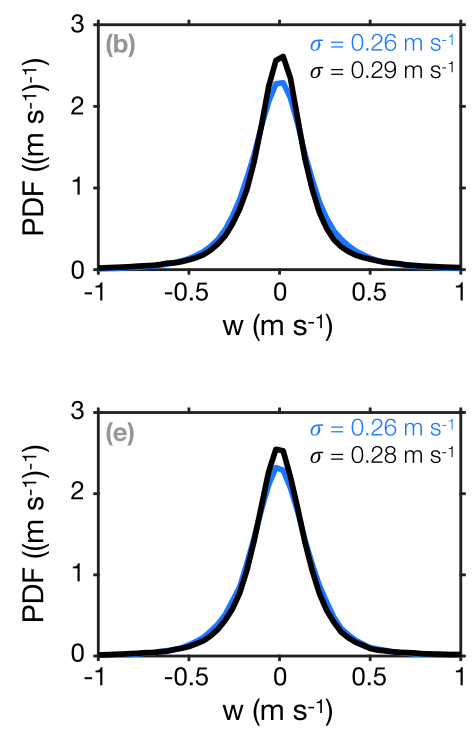

Thin Clouds

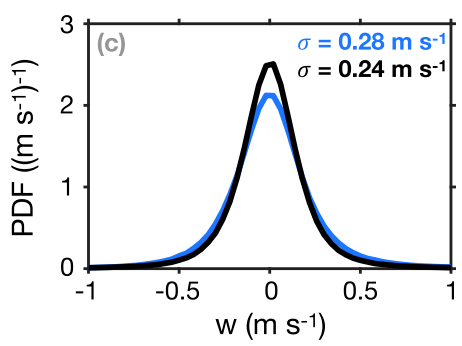

FIG. 10. High-frequency vertical air motion within elevated ice clouds. Cloud layers are separated into (left) thick, (center) medium, and (right) thin categories based on geometric thickness thresholds of 4 and $2 \mathrm{~km}$ as determined by the MMCR. Data are further composited into vertical intervals corresponding to (top) 0-2, (middle) 2-4, and (bottom) more than $4 \mathrm{~km}$ below the MMCR-derived cloud top. The PDF of vertical air motion is shown for day and night conditions, which correspond to 0900-1500 LT and 2100-0300 LT, respectively. The standard deviation $(\sigma)$ of vertical motion is indicated in the upper right, and bold values indicate that the day and night standard deviations are significantly different at the $95 \%$ confidence level. Data are from the MMCR.

time interval for the day composite is shifted from before so that air motion is examined at midday. The cloud layers are then separated based on cloud geometric thickness as determined by the MMCR. Thick, medium, and thin composites are generated based on cloud geometric thickness values greater than $4 \mathrm{~km}$, between 4 and $2 \mathrm{~km}$, and less than $2 \mathrm{~km}$, respectively. The cloud layers are further divided into vertical intervals corresponding to $0-2,2-4$, and more than $4 \mathrm{~km}$ below the MMCR-derived cloud top. Note that the MMCR typically underestimates the cloud-top height relative to the A-Train satellites, so the cloud-thickness thresholds used to define thick, medium, and thin clouds are lower bounds for the values that would be reported by the A-Train. This is important when considering the results in conjunction with the heating rates presented in Fig. 5.
Distributions of high-frequency vertical air motion within elevated ice clouds are shown in Fig. 10. For thick clouds, the standard deviation of air motion is largest in the top $2 \mathrm{~km}$ of the cloud, perhaps because the cloud top is more exposed to the effects of radiation than the cloud interior. The standard deviation in the top $2 \mathrm{~km}$ of the cloud is also significantly larger at night than during the day. At this level, the vertical profile of radiative heating destabilizes the cloud at night and is more vertically uniform during the day, so the stronger air motion at night could be caused by enhanced radiatively driven turbulence (Fig. 5). No diurnal variation of air motion is found in the lower regions of thick clouds or at any level in medium clouds. In contrast, the standard deviation of air motion is larger during the day in thin clouds. 


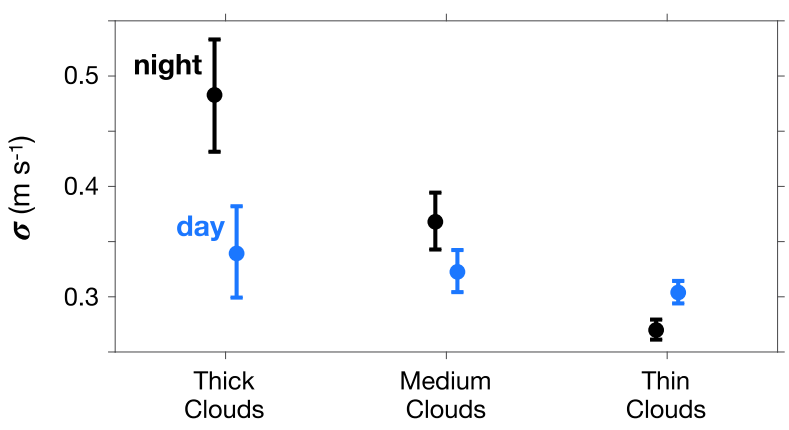

FIG. 11. High-frequency vertical air motion at the highest level in the cloud where data are available. The line labeled $w$ level in Fig. 5 shows an estimate of where this level occurs. The thick, medium, and thin cloud categories are determined based on geometric thickness thresholds of 4 and $2 \mathrm{~km}$ as determined by the MMCR The standard deviation $(\sigma)$ of vertical air motion is plotted, and the error bars show the $95 \%$ confidence interval. Day and night composites correspond to $0900-1500 \mathrm{LT}$ and $2100-0300 \mathrm{LT}$, respectively. Data are from the MMCR.

An analysis of air motion near the cloud top is presented in Fig. 11. In this figure the topmost data point from each cloud layer is considered, which typically occurs at the height of the $w$ level line in Fig. 5. At this level, the air motion is also enhanced at night in thick clouds and enhanced during the day in thin clouds, but the nighttime invigoration of air motion in thick clouds is even stronger. For thick clouds, diurnal variations of radiative heating have the largest effect on air motion near cloud top.

The fact that thick and thin clouds have diurnal cycles of air motion that are out of phase suggests a length scale for the processes that drive the air motion. Thick and thin cloud elements are often physically connected to one another within a single anvil cloud, so the mechanism that causes thick and thin clouds to have out-ofphase cycles must be confined to a horizontal scale that is smaller than the size of a typical anvil. Gravity waves undoubtedly contribute to the observed air motion, but they propagate over larger spatial scales, so diurnal variations of gravity wave activity will cause diurnal variations of air motion that have the same sign in thick and thin clouds. This means that a smaller-scale process must contribute to the diurnal cycle of air motion as well. Thus, it is likely that diurnal variations of turbulence cause the diurnal cycle of air motion to be out of phase in thick and thin clouds.

The difference between the diurnal cycle of turbulence in thick and thin clouds also suggests that the mechanism by which solar radiation affects turbulence may be different in the two cases. Hartmann et al. (2018) argued that vertical gradients of radiative heating are the primary mechanism by which radiation drives turbulence in optically thick and intermediate anvil cloud. At night, longwave radiation cools the cloud top and warms the cloud base, destabilizing the cloud and exciting turbulence. During daytime, shortwave radiation preferentially heats the cloud top, so it may reduce the overall turbulent activity in the cloud (Fig. 5). Meanwhile, Starr and Cox (1985) argued that for optically thin clouds, shortwave heating is more uniform with height, so it affects turbulence by amplifying small-scale horizontal heating gradients instead. For instance, if a turbulent overturning cell develops in a thin-cloud layer, then the ice crystals will grow in the updraft. This enhances shortwave absorption there, which increases the updraft buoyancy and amplifies the turbulence. The fact that the presence of shortwave radiation is associated with reduced air motion in thick clouds and enhanced air motion in thin clouds is consistent with these proposed mechanisms.

These findings suggest that radiative heating of high clouds affects the turbulence within them. This is consistent with the microphysical cycling theory. We will now investigate the second aspect of this theory, which is that the turbulence is sufficiently vigorous to regularly cause ice nucleation in anvil clouds.

The possibility of ice nucleation occurring in anvil clouds is investigated using ice-crystal number concentration $\left(N_{\text {ice }}\right)$ data from the A-Train satellites. We analyze $N_{\text {ice }}$ near the cloud top because this region typically has the most reliable data and the most favorable conditions for ice nucleation (section 2a; Jensen and Ackerman 2006; Mitchell et al. 2018). For each scene, $N_{\text {ice }}$ is selected from the highest level at which the radar and lidar from CloudSat and CALIPSO both detect a cloud. As before, we study clouds that are detected by radar, so the analysis represents anvil clouds but not thin cirrus. The average position of the level from which $N_{\text {ice }}$ data are selected is shown by the line labeled " $N$ ice level" in Fig. 5 . This level is vertically close to the $w$ level, so the $N_{\text {ice }}$ data and the air motion plotted in Fig. 11 represent nearly the same level in the cloud (see appendix A).

Figure 12 shows $N_{\text {ice }}$ binned by cloud geometric thickness, which in this case approximately corresponds to the cloud thickness values used in Fig. 5. The data are further binned by temperature to control for its effect on ice nucleation (Koop et al. 2000). Figures 12a and 12b show the median values of $N_{\text {ice }}$ for the day and night satellite overpasses, which occur around 1330 and 0130 LT, respectively. The difference between day and night is shown in Fig. 12c. As in the diurnal cycle of highfrequency air motion near the cloud top, thick clouds and thin clouds have diurnal variations of $N_{\text {ice }}$ that are out of phase. Clouds thicker than $6 \mathrm{~km}$ with temperatures colder than $-65^{\circ} \mathrm{C}$ have significantly larger concentrations of ice crystals during the day, with one exception being clouds that are $6-8 \mathrm{~km}$ thick with 
(a) Day (1330 LT)

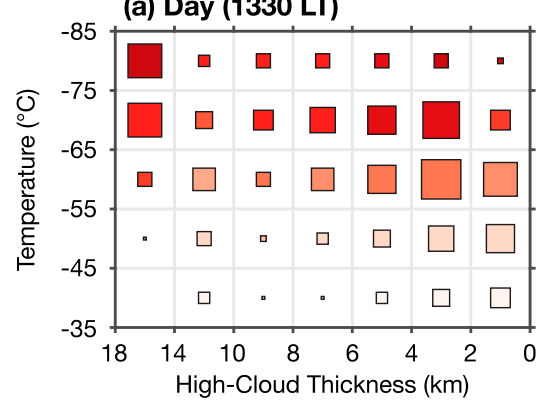

(b) Night (0130 LT)

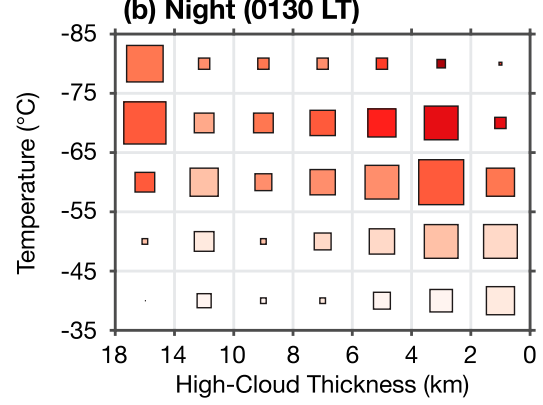

(c) Difference

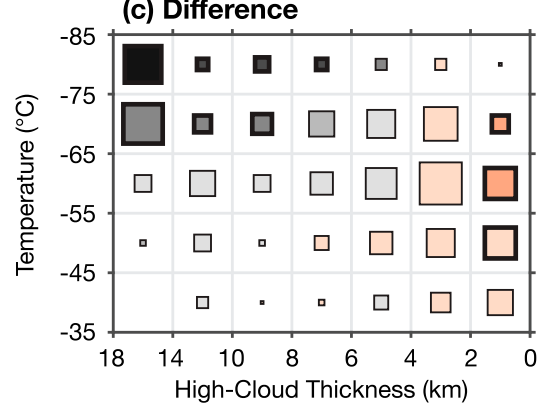

Nice $\left(\# L^{-1}\right)$

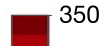

300

250

200

$-150$

$-100$

$-50$

0

FIG. 12. Ice-crystal number concentration $\left(N_{\text {ice }}\right)$ at the highest level where the CloudSat radar and CALIPSO lidar both detect a cloud. The line labeled $N_{\text {ice }}$ level in Fig. 5 shows the average position of this level. $N_{\text {ice }}$ is plotted as a function of temperature and cloud geometric thickness. (a) Colors show the median value of $N_{\text {ice }}$ for the daytime satellite overpasses, which occur around 1330 LT. The size of the squares is proportional to the number of observations. (b) As in (a), but showing the nighttime overpasses, which occur around 0130 LT. (c) The difference between day and night. Thick outlines indicate that the differences are statistically significant at the $95 \%$ confidence level. Data are from the A-Train satellites (DARDAR-Nice).

temperatures between $-65^{\circ}$ and $-75^{\circ} \mathrm{C}$. Meanwhile, clouds thinner than $2 \mathrm{~km}$ with temperatures between $-45^{\circ}$ and $-75^{\circ} \mathrm{C}$ have larger ice concentrations at night. The day-night difference is about $20 \%-50 \%$ of the day and night median values, so it is substantial. Note that the thicker clouds have stronger air motion and smaller $N_{\text {ice }}$ at night, and the thinner clouds have stronger air motion and smaller $N_{\text {ice }}$ during the day. In both cases stronger air motion is associated with a reduced concentration of ice crystals.

The fact that high-frequency air motion is inversely related to $N_{\text {ice }}$ near the cloud top indicates that turbulence in anvil clouds depletes or disperses ice crystals at a faster rate than it creates them. This suggests that the turbulent updrafts are typically not strong enough to produce the conditions necessary for ice nucleation. If an air parcel rises in a cloud and becomes supersaturated with respect to ice, then the preexisting ice in the parcel will grow by vapor deposition. Ice nucleation only occurs if the rising motion is sufficiently fast and long-lasting that supersaturation increases substantially despite the ongoing vapor deposition onto the preexisting ice. For temperatures typical of the upper troposphere, heterogeneous ice nucleation can occur if the relative humidity reaches $110 \%-150 \%$, while homogeneous nucleation can only occur if the relative humidity exceeds $\sim 150 \%$ (Krämer et al. 2016, 2020, manuscript submitted to Atmos. Chem. Phys. Discuss.). It may be that turbulence in anvil clouds is not vigorous enough to regularly cause these supersaturation values to occur, so instead its primary effect on $N_{\text {ice }}$ is to enhance entrainment of environmental air into the cloud and thereby disperse the ice crystals over a larger volume of air. Turbulence could also reduce $N_{\text {ice }}$ if the entrainment completely sublimates some of the ice crystals in the cloud. This process is thought to be inefficient in the upper troposphere, however, so it may not be the primary explanation for the diurnal variation of $N_{\text {ice }}$ (Seeley et al. 2019). In any case, the most favorable conditions for ice nucleation in anvil clouds typically occur near cloud top (Jensen and Ackerman 2006; Mitchell et al. 2018), yet our findings indicate that stronger turbulence does not enhance ice nucleation there. This suggests that the microphysical cycling mechanism is not the dominant process by which radiative heating affects the life cycle of anvil clouds.

\section{c. Investigating the anvil lifting mechanism}

The anvil lifting mechanism is another possible explanation for the diurnal variation of anvil clouds. This process involves mesoscale circulation, so the MMCR data cannot be used to investigate it (section 2b). Instead, we investigate this process by considering the atmospheric heat budget.

The large-scale heat budget of the tropical atmosphere involves a balance between diabatic heating and the storage and advection of energy. This can be expressed using the apparent heat source of Yanai et al. (1973):

$$
Q_{1} \approx \frac{\partial \bar{s}}{\partial t}+\bar{w} \frac{\partial \bar{s}}{\partial z}
$$

where $Q_{1}$ is the apparent heat source from radiation and convection, $s=c_{p} T+g z$ is dry static energy, $c_{p}$ is the 
specific heat of dry air at constant pressure, $T$ is temperature, $g$ is gravity, $w$ is vertical velocity, and overbars indicate horizontal averages over scales that are much larger than individual convective elements. The right side of this equation should have a term that represents horizontal advection of dry static energy, but this term is negligible because the small Coriolis parameter in the tropics prevents the atmosphere from sustaining largescale horizontal temperature gradients. Furthermore, for time scales that exceed those of gravity wave adjustment, the time-tendency term vanishes, and a balance arises between the heating from radiation and convection and the adiabatic warming and cooling from vertical motion:

$$
Q_{1} \approx \bar{w} \frac{\partial \bar{s}}{\partial z} .
$$

This relation is called weak temperature gradient (WTG) balance (Sobel et al. 2001).

Mesoscale circulations within tropical anvil clouds adjust to WTG balance on a time scale of several hours, so they approximately maintain WTG balance throughout the diurnal cycle (Ruppert and Hohenegger 2018). The WTG relationship can therefore be used to estimate the vertical motion that is caused by the anvil lifting mechanism. We estimate this quantity using the average value of $\partial \bar{s} / \partial z$ at $z=13 \mathrm{~km}$ and values of $Q_{1}$ that correspond to typical radiative heating rates in high clouds with geometric thickness between 2 and $6 \mathrm{~km}$ (Fig. 5). Cloud radiative heating is about $10 \mathrm{~K} \mathrm{day}^{-1}$ during midday, which corresponds to a mesoscale updraft of $7 \mathrm{~cm} \mathrm{~s}^{-1}$ within the anvil. This is comparable to the fall speed of ice crystals with a diameter of $50 \mu \mathrm{m}$, which are common in aged anvil clouds (Heymsfield et al. 2013; Lawson et al. 2010). Thus, the updraft may slow the sedimentation of the cloud into lower levels of the atmosphere where the warmer air can sublimate cloud particles. For example, a particle settling at a rate of $7 \mathrm{~cm} \mathrm{~s}^{-1}$ would fall $3 \mathrm{~km}$ over a period of $12 \mathrm{~h}$. If the particle starts at an altitude of $13 \mathrm{~km}$, then this corresponds to a $\sim 25 \mathrm{~K}$ warming of the ambient air. The mesoscale updraft offsets this gravitational settling, which delays the sublimation of cloud particles and extends the cloud lifetime. This process is most pronounced during daytime, when cloud radiative heating is strongest. Assuming that the LW radiative heating in Fig. 5 represents the nighttime heating rate in anvil clouds, then a typical nighttime heating rate is about $3 \mathrm{~K}_{\text {day }}{ }^{-1}$. This corresponds to a mesoscale updraft of $2 \mathrm{~cm} \mathrm{~s}^{-1}$, which is much smaller than the daytime value. These estimates suggest that the anvil lifting mechanism could be responsible for the diurnal variation of the anvil life cycle.

\section{Discussion}

The idea that interactions among radiation, microphysics, and small-scale circulation affect the development of high clouds was introduced several decades ago and has since been investigated in numerous modeling studies. Model simulations generally support the idea that radiative heating affects high clouds, though the mechanisms of cloud-radiation interaction are still under debate (Starr and Cox 1985; Boehm et al. 1999; Dinh et al. 2010; Hartmann et al. 2018). It is difficult to draw firm conclusions about these mechanisms from numerical simulations alone because current models are sensitive to microphysical parameterizations. Progress on this topic will therefore require stronger observational constraints on high-cloud processes. In this study we show direct observational evidence that diurnal variations of cloud radiative heating affect the life cycle of tropical anvil clouds. This means that if theories on cloud-radiation interaction can be posed in a way that invokes the diurnal cycle, then it may be possible to test them using observations. Our investigation of the microphysical cycling and anvil lifting mechanisms is one example of this approach, but it may be possible to use the diurnal cycle to test other theories as well.

Our findings also have relevance for understanding the tropical radiation balance. It has long been observed that the radiation balance over the tropical warm pools is almost the same in convective and adjacent nonconvective regions, despite the fact that the albedo and greenhouse effect of deep convective clouds are both large (Ramanathan et al. 1989; Hartmann et al. 2001; Wall et al. 2019). Why the radiation balance is nearly uniform is an open question, but previous studies have argued that it may be a result of the way in which radiative heating affects the anvil life cycle. Hartmann et al. (2018) hypothesized that the natural life cycle of anvil clouds produces optically thick and optically thin clouds whose radiative effects nearly cancel out, causing the radiation balance to be similar in convective and adjacent nonconvective regions. They further hypothesized that cloud radiative heating is critical to achieving the cancellation because it lofts anvil clouds and because it extends the cloud lifetime through the microphysical cycling mechanism. Our findings are consistent with their hypothesis that radiative heating lofts anvil clouds, but our findings are inconsistent with their hypothesis that the microphysical cycling mechanism is critical to the anvil life cycle. Thus, in our view, it would be 
valuable to revisit this theory and focus on the effects of radiative lofting of anvil clouds.

\section{Conclusions}

In this study we use observations to investigate how diurnal variations of cloud radiative heating affect the development of anvil clouds over the tropical western Pacific Ocean. Longwave radiation heats the base of high-cloud layers and cools the top of high clouds that are thicker than $2 \mathrm{~km}$, while shortwave radiation heats the entire cloud and preferentially heats the cloud top. The shortwave and longwave effects have similar magnitudes during midday, but only the longwave effect occurs at night, so high clouds experience a substantial diurnal cycle of radiative heating.

We further show that these diurnal variations of radiative heating affect the life cycle of anvil clouds. Anvil clouds are more persistent, more laterally expansive, or both when they are heated by the sun. This cannot be explained by diurnal variations of convective intensity, geographic patterns of convection, or satellite retrieval errors. Furthermore, diurnal variations of environmental temperature and humidity are expected to extend the anvil lifetime at night, so these effects do not explain the diurnal variation of anvil clouds either. These findings indicate that shortwave heating causes anvil clouds to persist longer or spread over a larger area.

We then investigate if the microphysical cycling mechanism could cause the diurnal variation of anvil clouds. According to this theory, radiative heating drives turbulent overturning within anvil clouds that can be sufficiently vigorous to cause nucleation of ice particles in the updrafts. It is posited that this mechanism continues to nucleate ice as the anvil evolves and therefore extends the cloud lifetime. We investigate this idea by studying high clouds that are detected by radar, which typically include anvils but not thin cirrus. An inverse relationship is found between high-frequency air motion and ice-crystal number concentration near cloud top, indicating that turbulence within anvil clouds depletes or disperses ice crystals at a faster rate than it nucleates them. This finding suggests that the microphysical cycling mechanism may have a minor influence on the anvil life cycle, and that another mechanism causes the diurnal variation of anvil clouds.

One limitation of our analysis is that turbulence and ice-crystal number concentration are studied near cloud top. If ice nucleation occurs in lower regions of anvil clouds that are not in contact with the cloud top through turbulent mixing, then it would not be detected in our analysis. The strongest turbulence and the most favorable conditions for ice nucleation typically occur near cloud top, however, so if nucleation does not occur there, then it is unlikely to regularly occur elsewhere in the cloud (Fig. 10; Jensen and Ackerman 2006; Mitchell et al. 2018). Recent advancements in radar technology may soon provide in-cloud water vapor profiles that could help to investigate this further (Roy et al. 2018).

Since our findings indicate that solar heating modifies anvil clouds through a process other than the microphysical cycling mechanism, we hypothesize that the anvil lifting mechanism is the primary process by which radiative heating affects anvil cloud development. Radiative heating of anvil clouds creates a horizontal heating gradient between the cloud and the adjacent environment. This drives a mesoscale circulation that lifts and spreads the anvil (Fig. 1). We estimate that this circulation could offset the gravitational settling of cloud particles and extend the lifetime of anvil clouds. A similar process may occur in other types of high clouds as well. For instance, it has been argued that longwave heating affects thin tropopause cirrus in a similar way (Durran et al. 2009; Dinh et al. 2010). An important next step is to relate these findings and seek a theory for cloud-radiation interaction that applies to all types of elevated ice clouds.

Acknowledgments. This research is supported by the NOAA Climate and Global Change Postdoctoral Fellowship Program, administered by UCAR's Cooperative Programs for the Advancement of Earth System Science (CPAESS) under Award NA18NWS4620043B. We thank Heike Kalesse and Dennis Hartmann for helpful discussions, Robert Holzworth for sharing the lightning data, and James Ruppert for sharing a cartoon that was used to make Figure 1. We also thank the World Wide Lightning Location Network, which is a collaboration among over 50 research institutions around the world.

Data availability statement. All data used in this study are available online. The CERES and Himawari data were obtained from the Atmospheric Science Data Center of the NASA Langley Research Center and are available at https://earthdata.nasa.gov/ (CERES Science Team 2016, 2017a,b). The OLR data used in this study were rederived using updated methods and are available from the authors on request. The DARDAR-Nice data are available from the Cloud-Aerosol-WaterRadiation Interactions data and service center at http:// www.icare.univ-lille1.fr/ (Sourdeval 2019). The MMCR data are provided by the Atmospheric Radiation Measurement Program of the United States Department of Energy and can be downloaded from https://adc.arm.gov/ discovery/ (Kalesse 2013). The World Wide Lightning Location Network data are available at https://wwlln.net/, and the ERA-Interim data are available at https:// apps.ecmwf.int/datasets/ (ECMWF 2019). 


\section{APPENDIX A}

\section{Comparison of MMCR and A-Train Data}

Some of the evidence in this study compares data from the highest level in the cloud that is detected by the MMCR and data from the highest level in the cloud that is detected by the CloudSat radar (Figs. 11, 12). In this section we estimate the vertical offset between these levels to check if they represent similar parts of high clouds. Coincident measurements from these datasets do not exist because the A-Train orbit never passes directly above the MMCR, so a statistical comparison is made between MMCR data and CloudSat data from within $400 \mathrm{~km}$ of the MMCR site. In this comparison we must account for the fact that the MMCR only retrieves vertical air motion for cloud layers that satisfy strict conditional sampling: 1) The cloud base must be above $6 \mathrm{~km}, 2)$ the cloud layer must be colder than $-10^{\circ} \mathrm{C}, 3$ ) the cloud base must be at least $0.5 \mathrm{~km}$ above the top of all lower cloud layers, and 4) the 20-min-average hydrometeor fraction at a certain height must exceed $80 \%$. CloudSat data are screened to identify clouds that satisfy similar conditions to make a fair comparison. Conditions 1-3 are applied exactly to the CloudSat data, but condition 4 can only be approximated because CloudSat provides snapshot measurements. To approximate condition 4 it is required that the $30-\mathrm{km}$-average cloud fraction computed along the satellite track exceeds $80 \%$. A distance of $30 \mathrm{~km}$ is selected because an air parcel will travel that far in $20 \mathrm{~min}$ if it is moving with a velocity of $25 \mathrm{~m} \mathrm{~s}^{-1}$, which is a typical value for horizontal winds in the upper troposphere. The CloudSat-derived cloud layers that satisfy these conditions are then compared with the MMCR-derived cloud layers. Since similar conditional sampling is applied in both cases, any remaining differences in cloud-top height are primarily due to differences in instrument sensitivity or viewing geometry. Note that the screening of CloudSat data is only applied in this comparison, not in the analysis of A-Train data elsewhere in this study.

Figure A1 shows a comparison of the distribution of cloud-top height estimated by the MMCR and by CloudSat. The cloud-top height for the highest cloud layer in each scene is considered in this calculation. The distributions are similar overall, but CloudSat tends to report a slightly higher cloud top by $0.28 \mathrm{~km}$ on average. This offset is smaller than the vertical scale of turbulence in anvil clouds, so it will not affect the main conclusion about the relationship between turbulence and $N_{\text {ice }}$ near the top of anvils.

Another important sampling difference is that the A-Train provides data for thicker cloud layers than

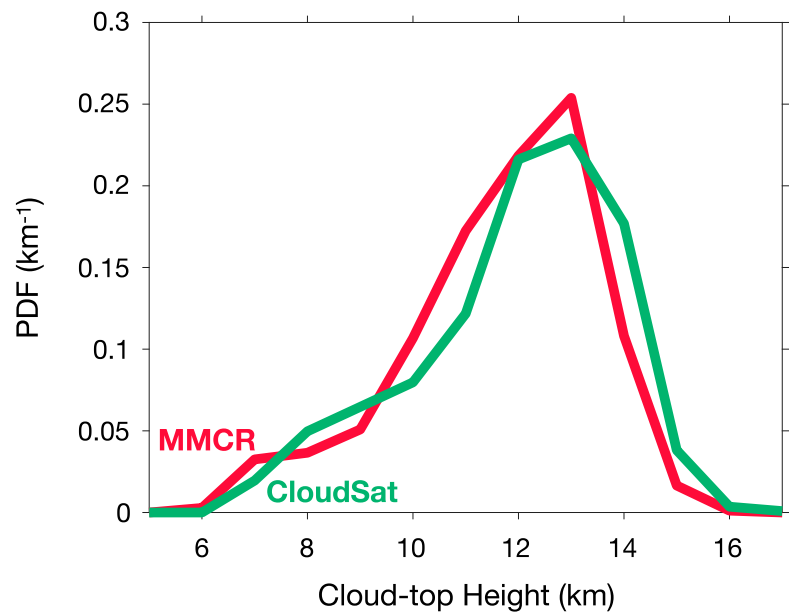

FIG. A1. Comparison of cloud-top height retrieved by the MMCR and CloudSat radar. CloudSat data are screened to identify cloud layers that satisfy similar conditions to those used in the MMCR retrieval, so the differences shown here are due to instrument sensitivity and viewing geometry. The PDF is shown for the cloud-top height from the highest cloud layer in each scene.

the MMCR. To estimate this difference, we compute the range of cloud thicknesses seen by the MMCR and then adjust these values to account for the fact that the MMCR underestimates the cloud-top height relative to the A-Train. The adjusted cloud thickness is computed as the MMCR-derived cloud thickness plus the average difference between the MMCR-derived cloud-top height and the CloudSat-derived cloud-top height (Fig. A1) plus the average difference between the CloudSat-derived cloud-top height and the CCCM-derived cloud-top height (Fig. 5). The thickest cloud layers for which vertical air motion can be retrieved are $\sim 8 \mathrm{~km}$ as determined by the MMCR or $\sim 9 \mathrm{~km}$ as determined by CCCM.

\section{APPENDIX B}

\section{Correction for Solar Noise in the CALIPSO Lidar Signal}

Noise from solar radiation is known to affect the CALIPSO lidar signal. This can be seen in Fig. B1, which shows the distribution of ice water content for cloud layers detected by lidar only. Ice water content values below $2 \times 10^{-6} \mathrm{~kg} \mathrm{~m}^{-3}$ are detected much less often during daytime because the backscatter signal from these clouds does not stand out above the noise from solar radiation. Anvil clouds typically have a diffuse layer with very low ice content near the cloud top, so similar anvil clouds will appear geometrically thicker at night than during the day if the default CloudSat/ CALIPSO cloud mask is used. To correct for this 


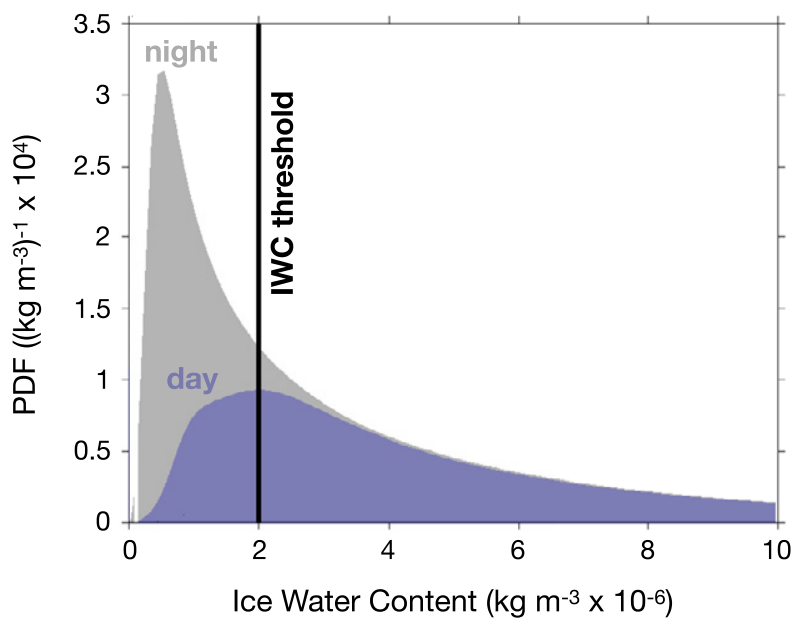

FIG. B1. Distribution of ice water content (IWC) in clouds detected only by the lidar on CALIPSO. The PDF is shown for the day and night satellite overpasses. Values below the IWC threshold of $2 \times 10^{-6} \mathrm{~kg} \mathrm{~m}^{-3}$ are detected much less often during daytime because of solar noise. Data are from the A-Train satellites (DARDAR-Nice).

sampling bias, we modify the cloud mask so that the range bins with ice water content below the threshold indicated in Fig. B1 are considered to be cloud free. This modification is necessary to make a fair comparison between day and night conditions in Fig. 12. Note that the cloud-mask modification only affects the cloud geometric thickness, not the retrievals of $N_{\text {ice. }}$.

\section{REFERENCES}

Abarca, S. F., K. L. Corbosiero, and T. J. Galarneau Jr., 2010: An evaluation of the Worldwide Lightning Location Network (WWLLN) using the National Lightning Detection Network (NLDN) as ground truth. J. Geophys. Res., 115, D18206, https://doi.org/10.1029/2009JD013411.

Ackerman, T. P., and G. M. Stokes, 2003: The Atmospheric Radiation Measurement Program. Phys. Today, 56, 38-44, https:// doi.org/10.1063/1.1554135.

— K.-N. Liou, F. P. J. Valero, and L. Pfister, 1988: Heating rates in tropical anvils. J. Atmos. Sci., 45, 1606-1623, https://doi.org/ 10.1175/1520-0469(1988)045<1606:HRITA>2.0.CO;2.

Berry, E., and G. G. Mace, 2014: Cloud properties and radiative effects of the Asian summer monsoon derived from A-Train data. J. Geophys. Res. Atmos., 119, 9492-9508, https://doi.org/ 10.1002/2014JD021458.

Bessho, K., and Coauthors, 2016: An introduction to Himawari-8/ 9-Japan's new-generation geostationary meteorological satellites. J. Meteor. Soc. Japan, 94, 151-183, https://doi.org/ 10.2151/jmsj.2016-009.

Boehm, M. T., J. Verlinde, and T. P. Ackerman, 1999: On the maintenance of high tropical cirrus. J. Geophys. Res., 104, 24423-24433, https://doi.org/10.1029/1999JD900798.

CERES Science Team, 2016: CERES CCCM, version RelB1. Accessed 22 July 2016, https://ceres.larc.nasa.gov/products.php? product $=\mathrm{CCCM}$.
— , 2017a: CER_GEO_Ed4_HIM08 Pixel-level dataset, version 1.0. Accessed 28 November 2017, https://search.earthdata.nasa.gov/ search?q=CER_GEO_Ed4_HIM08.

_ 2017b: CERES_SSF1deg_Ed4A data quality summary (5/16/ 2017). NASA, 43 pp., https://ceres.larc.nasa.gov/documents/ DQ_summaries/CERES_SSF1deg_Ed4A_DQS.pdf.

Chen, S. S., and R. A. Houze, 1997: Diurnal variation and life-cycle of deep convective systems over the tropical Pacific warm pool. Quart. J. Roy. Meteor. Soc., 123, 357-388, https://doi.org/ 10.1002/qj.49712353806.

Chepfer, H., H. Brogniez, and V. Noel, 2019: Diurnal variations of cloud and relative humidity profiles across the tropics. Sci. Rep., 9, 16045, https://doi.org/10.1038/s41598-019-52437-6.

Ciesielski, P. E., R. H. Johnson, W. H. Schubert, and J. H. Ruppert, 2018: Diurnal cycle of the ITCZ in DYNAMO. J. Climate, 31, 4543-4562, https://doi.org/10.1175/JCLI-D-17-0670.1.

Dai, A., 2001: Global precipitation and thunderstorm frequencies. Part II: Diurnal variations. J. Climate, 14, 1112-1128, https://doi.org/ 10.1175/1520-0442(2001)014\%3C1112:GPATFP\%3E2.0.CO;2.

Dee, D. P., and Coauthors, 2011: The ERA-Interim reanalysis: Configuration and performance of the data assimilation system. Quart. J. Roy. Meteor. Soc., 137, 553-597, https://doi.org/ 10.1002/qj.828.

Dinh, T. P., D. R. Durran, and T. P. Ackerman, 2010: Maintenance of tropical tropopause layer cirrus. J. Geophys. Res., 115, D02104, https://doi.org/10.1029/2009JD012735.

Dobbie, S., and P. Jonas, 2001: Radiative influences on the structure and lifetime of cirrus clouds. Quart. J. Roy. Meteor. Soc., 127, 2663-2682, https://doi.org/10.1002/qj.49712757808.

Doelling, D. R., M. Sun, L. T. Nguyen, M. L. Nordeen, C. O. Haney, D. F. Keyes, and P. F. Mlynczak, 2016: Advances in geostationary-derived longwave fluxes for the CERES synoptic (SYN1deg) product. J. Atmos. Oceanic Technol., 33, 503-521, https://doi.org/10.1175/JTECH-D-15-0147.1.

Dowden, R. L., J. B. Brundell, and C. J. Rodger, 2002: VLF lightning location by time of group arrival (TOGA) at multiple sites. J. Atmos. Sol.-Terr. Phys., 64, 817-830, https:// doi.org/10.1016/S1364-6826(02)00085-8.

Durran, D. R., T. Dinh, M. Ammerman, and T. Ackerman, 2009: The mesoscale dynamics of thin tropical tropopause cirrus. J. Atmos. Sci., 66, 2859-2873, https://doi.org/10.1175/2009JAS3046.1.

ECMWF, 2019: ERA-Interim Project. Accessed 21 June 2019, http://apps.ecmwf.int/datasets/.

Feng, Z., L. R. Leung, R. A. Houze, S. Hagos, J. Hardin, Q. Yang, B. Han, and J. Fan, 2018: Structure and evolution of mesoscale convective systems: Sensitivity to cloud microphysics in convectionpermitting simulations over the United States. J. Adv. Model. Earth Syst., 10, 1470-1494, https://doi.org/10.1029/2018MS001305.

Fiolleau, T., and R. Roca, 2013: An algorithm for the detection and tracking of tropical mesoscale convective systems using infrared images from geostationary satellite. IEEE Trans. Geosci. Remote Sens., 51, 4302-4315, https://doi.org/10.1109/TGRS.2012.2227762.

Fu, Q., S. K. Krueger, K. N. Liou, Q. Fu, S. K. Krueger, and K. N. Liou, 1995: Interactions of radiation and convection in simulated tropical cloud clusters. J. Atmos. Sci, 52, 1310-1328, https://doi.org/10.1175/ 1520-0469(1995)052<1310:IORACI > 2.0.CO;2.

Gallagher, M. W., and Coauthors, 2012: Observations and modelling of microphysical variability, aggregation and sedimentation in tropical anvil cirrus outflow regions. Atmos. Chem. Phys., 12, 6609-6628, https://doi.org/10.5194/acp-12-6609-2012.

Garrett, T. J., and Coauthors, 2005: Evolution of a Florida cirrus anvil. J. Atmos. Sci., 62, 2352-2372, https://doi.org/10.1175/ JAS3495.1. 
_ M. A. Zulauf, and S. K. Krueger, 2006: Effects of cirrus near the tropopause on anvil cirrus dynamics. Geophys. Res. Lett., 33, L17804, https://doi.org/10.1029/2006GL027071.

Gasparini, B., P. N. Blossey, D. L. Hartmann, G. Lin, and J. Fan, 2019: What drives the life cycle of tropical anvil clouds? J. Adv. Model. Earth Syst., 11, 2586-2605, https://doi.org/10.1029/ 2019MS001736.

Gray, W. M., and R. W. Jacobson, 1977: Diurnal variation of deep cumulus convection. Mon. Wea. Rev., 105, 1171-1188, https://doi.org/ 10.1175/1520-0493(1977)105<1171:DVODCC > 2.0.CO;2.

Harrop, B., and D. L. Hartmann, 2016: The role of cloud radiative heating within the atmosphere on the high cloud amount and top-of-atmosphere cloud radiative effect. J. Adv. Model. Earth Syst., 8, 1391-1410, https://doi.org/10.1002/2016MS000670.

Hartmann, D. L., and S. E. Berry, 2017: The balanced radiative effect of tropical anvil clouds. J. Geophys. Res. Atmos., 122, 5003-5020, https://doi.org/10.1002/2017JD026460.

- H. H. Hendon, and R. A. Houze, 1984: Some implications of the mesoscale circulations in tropical cloud clusters for large-scale dynamics and climate. J. Atmos. Sci., 41, 113-121, https://doi.org/ 10.1175/1520-0469(1984)041<0113:SIOTMC > 2.0.CO;2.

- L. A. Moy, and Q. Fu, 2001: Tropical convection and the energy balance at the top of the atmosphere. J. Climate, 14, 4495-4511, https://doi.org/10.1175/1520-0442(2001)014<4495: TCATEB $>2.0 . \mathrm{CO} ; 2$.

— - B. Gasparini, S. E. Berry, and P. N. Blossey, 2018: The life cycle and net radiative effect of tropical anvil clouds. J. $A d v$. Model. Earth Syst., 10, 3012-3029, https://doi.org/10.1029/ 2018MS001484.

Heymsfield, A. J., C. Schmitt, and A. Bansemer, 2013: Ice cloud particle size distributions and pressure-dependent terminal velocities from in situ observations at temperatures from $0^{\circ}$ to $-86^{\circ}$ C. J. Atmos. Sci., 70, 4123-4154, https://doi.org/ 10.1175/JAS-D-12-0124.1.

Houze, R. A., 1982: Cloud clusters and large-scale vertical motions in the tropics. J. Meteor. Soc. Japan, 60, 396-410, https:// doi.org/10.2151/jmsj1965.60.1_396.

Hutchins, M. L., R. H. Holzworth, J. B. Brundell, and C. J. Rodger, 2012: Relative detection efficiency of the World Wide Lightning Location Network. Radio Sci., 47, RS6005, https://doi.org/ 10.1029/2012RS005049.

Igel, M. R., A. J. Drager, and S. C. van den Heever, 2014: A CloudSat cloud object partitioning technique and assessment and integration of deep convective anvil sensitivities to sea surface temperature. J. Geophys. Res. Atmos., 119, 1051510 535, https://doi.org/10.1002/2014JD021717.

Jacobson, A. R., R. Holzworth, J. Harlin, R. Dowden, and E. Lay, 2006: Performance assessment of the World Wide Lightning Location Network (WWLLN), using the Los Alamos Sferic Array (LASA) as ground truth. J. Atmos. Oceanic Technol., 23, 1082-1092, https://doi.org/10.1175/JTECH1902.1.

Jensen, E. J., and A. S. Ackerman, 2006: Homogeneous aerosol freezing in the tops of high-altitude tropical cumulonimbus clouds. Geophys. Res. Lett., 33, L08802, https://doi.org/10.1029/2005GL024928.

_- and Coauthors, 2009: On the importance of small ice crystals in tropical anvil cirrus. Atmos. Chem. Phys., 9, 5519-5537, https://doi.org/10.5194/acp-9-5519-2009.

_ S. C. van den Heever, and L. D. Grant, 2018: The life cycles of ice crystals detrained from the tops of deep convection. J. Geophys. Res. Atmos., 123, 9624-9634, https://doi.org/10.1029/2018JD028832.

Kalesse, H., 2013: ICECLDVERTVEL. Atmospheric Radiation Measurement Program Data Center, accessed 13 June 2019, http://doi.org/10.5439/1169516.
— and P. Kollias, 2013: Climatology of high cloud dynamics using profiling arm Doppler radar observations. J. Climate, 26, 6340-6359, https://doi.org/10.1175/JCLI-D-12-00695.1.

Kato, S., S. Sun-Mack, W. F. Miller, F. G. Rose, Y. Chen, P. Minnis, and B. A. Wielicki, 2010a: Relationships among cloud occurrence frequency, overlap, and effective thickness derived from CALIPSO and CloudSat merged cloud vertical profiles. J. Geophys. Res., 115, D00H28, https://doi.org/10.1029/2009JD012277.

_ W. W. Miller, S. Sun-Mack, F. G. Rose, Y. Chen, and P. E. Mlynczak, 2010b: Variable descriptions of the A-train integrated CALIPSO, CloudSat, CERES, and MODIS merged product (CCCM or C3M). NASA, 54 pp., https://asdc.larc.nasa.gov/documents/ceres/readme/ c3m_variables_B1_v2.pdf.

_ and Coauthors, 2011: Improvements of top-of-atmosphere and surface irradiance computations with CALIPSO-, CloudSat-, and MODIS-derived cloud and aerosol properties. J. Geophys. Res., 116, D19209, https://doi.org/10.1029/2011JD016050.

Koop, T., B. Luo, A. Tsias, and T. Peter, 2000: Water activity as the determinant for homogeneous ice nucleation in aqueous solutions. Nature, 406, 611-614, https://doi.org/10.1038/35020537.

Krämer, M., and Coauthors, 2016: A microphysics guide to cirrus clouds-Part 1: Cirrus types. Atmos. Chem. Phys., 16, 3463 3483, https://doi.org/10.5194/acp-16-3463-2016.

Kraus, E. B., 1963: The diurnal precipitation change over the sea. J. Atmos. Sci., 20, 551-556, https://doi.org/10.1175/1520-0469(1963) $020<0551$ :TDPCOT $>2.0 . \mathrm{CO} ; 2$.

Lawson, R. P., E. Jensen, D. L. Mitchell, B. Baker, Q. Mo, and B. Pilson, 2010: Microphysical and radiative properties of tropical clouds investigated in TC4 and NAMMA. J. Geophys. Res., 115, D00J08, https://doi.org/10.1029/2009JD013017. , and Coauthors, 2019: A review of ice particle shapes in cirrus formed in situ and in anvils. J. Geophys. Res. Atmos., 124, 10 049-10 090, https://doi.org/10.1029/2018JD030122.

Lilly, D. K., 1988: Cirrus outflow dynamics. J. Atmos. Sci., 45, 1594-1605, https://doi.org/10.1175/1520-0469(1988)045<1594:COD>2.0.CO;2.

Mace, G. G., M. Deng, B. Soden, and E. Zipser, 2006: Association of tropical cirrus in the 10-15-km layer with deep convective sources: An observational study combining millimeter radar data and satellite-derived trajectories. J. Atmos. Sci., 63, 480503, https://doi.org/10.1175/JAS3627.1.

McGill, M. J., M. A. Vaughan, C. R. Trepte, W. D. Hart, D. L. Hlavka, D. M. Winker, and R. Kuehn, 2007: Airborne validation of spatial properties measured by the CALIPSO lidar. J. Geophys. Res., 112, D20201, https://doi.org/10.1029/2007JD008768.

Minnis, P., and Coauthors, 2008: Near-real time cloud retrievals from operational and research meteorological satellites. Proc. SPIE, 7107, 15-18, https://doi.org/10.1117/12.800344.

, and Coauthors, 2020: CERES MODIS cloud product retrievals for edition 4 -Part I: Algorithm changes. IEEE Trans. Geosci. Remote Sens., https://doi.org/10.1109/tgrs.2020.3008866, in press.

Mitchell, D. L., A. Garnier, J. Pelon, and E. Erfani, 2018: CALIPSO (IIR-CALIOP) retrievals of cirrus cloud iceparticle concentrations. Atmos. Chem. Phys., 18, 1732517354, https://doi.org/10.5194/acp-18-17325-2018.

Muhlbauer, A., H. Kalesse, and P. Kollias, 2014: Vertical velocities and turbulence in midlatitude anvil cirrus: A comparison between in situ aircraft measurements and ground-based Doppler cloud radar retrievals. Geophys. Res. Lett., 41, 7814-7821, https://doi.org/10.1002/2014GL062279.

Nesbitt, S. W., and E. J. Zipser, 2003: The diurnal cycle of rainfall and convective intensity according to three years of TRMM measurements. J. Climate, 16, 1456-1475, https://doi.org/10.1175/ 1520-0442-16.10.1456. 
Pope, M., C. Jakob, and M. J. Reeder, 2008: Convective systems of the north Australian monsoon. J. Climate, 21, 5091-5112, https:// doi.org/10.1175/2008JCLI2304.1.

Ramanathan, V., R. D. Cess, E. F. Harrison, P. Minnis, B. R. Barkstrom, E. Ahmad, and D. Hartmann, 1989: Cloud-radiative forcing and climate: Results from the Earth Radiation Budget Experiment. Science, 243, 57-63, https://doi.org/10.1126/science.243.4887.57.

Randall, D. A., Harshvardhan, and D. A. Dazlich, 1991: Diurnal variability of the hydrologic cycle in a general circulation model. J. Atmos. Sci., 48, 40-62, https://doi.org/10.1175/15200469(1991)048<0040:DVOTHC > 2.0.CO;2.

Rodger, C. J., S. Werner, J. B. Brundell, E. H. Lay, N. R. Thomson, R. H. Holzworth, and R. L. Dowden, 2006: Detection efficiency of the VLF World-Wide Lightning Location Network (WWLLN): Initial case study. Ann. Geophys., 24, 3197-3214, https://doi.org/10.5194/angeo-24-3197-2006.

Roy, R. J., M. Lebsock, L. Millán, R. Dengler, R. R. Monje, J. V. Siles, and K. B. Cooper, 2018: Boundary-layer water vapor profiling using differential absorption radar. Atmos. Meas. Tech., 11, 6511-6523, https://doi.org/10.5194/amt-11-6511-2018.

Ruppert, J. H., Jr., and C. Hohenegger, 2018: Diurnal circulation adjustment and organized deep convection. J. Climate, 31, 4899-4916, https://doi.org/10.1175/JCLI-D-17-0693.1.

— ward motion. Geophys. Res. Lett., 46, 2911-2921, https:// doi.org/10.1029/2018GL081806.

Schmidt, C. T., and T. J. Garrett, 2013: A simple framework for the dynamic response of cirrus clouds to local diabatic radiative heating. J. Atmos. Sci., 70, 1409-1422, https://doi.org/10.1175/ JAS-D-12-056.1.

Seeley, J. T., N. Jeevanjee, W. Langhans, and D. M. Romps, 2019: Formation of tropical anvil clouds by slow evaporation. Geophys. Res. Lett., 46, 492-501, https://doi.org/10.1029/2018GL080747.

Senf, F., D. Klocke, and M. Brueck, 2018: Size-resolved evaluation of simulated deep tropical convection. Mon. Wea. Rev., 146, 2161-2182, https://doi.org/10.1175/MWR-D-17-0378.1.

Sherwood, S. C., 1999: On moistening of the tropical troposphere by cirrus clouds. J. Geophys. Res., 104, 11 949-11960, https:// doi.org/10.1029/1999JD900162.

Sobel, A. H., J. Nilsson, and L. M. Polvani, 2001: The weak temperature gradient approximation and balanced tropical moisture waves. J. Atmos. Sci., 58, 3650-3665, https://doi.org/10.1175/ 1520-0469(2001)058<3650:TWTGAA $>2.0$. CO;2.

Sourdeval, O., 2019: DARDAR-Nice, version 1.0.0. Accessed 11 December 2019, https://web-backend.icare.univ-lille.fr/dardar-nice. , E. Gryspeerdt, M. Krämer, T. Goren, J. Delanoë, A. Afchine, F. Hemmer, and J. Quaas, 2018: Ice crystal number concentration estimates from lidar-radar satellite remote sensing_Part I: Method and evaluation. Atmos. Chem. Phys., 18, 14327-14350, https:// doi.org/10.5194/acp-18-14327-2018.

Starr, D. O., and S. K. Cox, 1985: Cirrus clouds. Part II: Numerical experiments on the formation and maintenance of cirrus. J. Atmos. Sci., 42, 2682-2694, https://doi.org/10.1175/15200469(1985)042<2682:CCPINE > 2.0.CO;2.

Stephens, G. L., and Coauthors, 2002: The CloudSat mission and the A-Train: A new dimension of space-based observations of clouds and precipitation. Bull. Amer. Meteor. Soc., 83, 17711790, https://doi.org/10.1175/BAMS-83-12-1771.

Tao, W. K., S. Lang, J. Simpson, C. H. Sui, B. Ferrier, and M. D. Chou, 1996: Mechanisms of cloud-radiation interaction in the tropics and midlatitudes. J. Atmos. Sci., 53, 2624-2651, https://doi.org/10.1175/1520-0469(1996)053<2624:MOCRII >2.0. $\mathrm{CO} ; 2$.

Trepte, Q. Z., and Coauthors, 2019: Global cloud detection for CERES edition 4 using Terra and Aqua MODIS data. IEEE Trans. Geosci. Remote Sens., 57, 9410-9449, https://doi.org/ 10.1109/tgrs.2019.2926620.

Virts, K. S., J. M. Wallace, M. L. Hutchins, and R. H. Holzworth, 2013: Highlights of a new ground-based, hourly global lightning climatology. Bull. Amer. Meteor. Soc., 94, 1381-1391, https://doi.org/10.1175/BAMS-D-12-00082.1.

Wall, C. J., and D. L. Hartmann, 2018: Balanced cloud radiative effects across a range of dynamical conditions over the tropical west Pacific. Geophys. Res. Lett., 45, 11 490-11498, https:// doi.org/10.1029/2018g1080046.

—, M. M. Thieman, W. L. Smith, and P. Minnis, 2018: The life cycle of anvil clouds and the top-of-atmosphere radiation balance over the tropical west Pacific. J. Climate, 31, 10059 10 080, https://doi.org/10.1175/JCLI-D-18-0154.1.

,,-- and J. R. Norris, 2019: Is the net cloud radiative effect constrained to be uniform over the tropical warm pools? Geophys. Res. Lett., 46, 12495-12503, https://doi.org/10.1029/ $2019 \mathrm{gl} 083642$.

Winker, D. M., W. H. Hunt, and M. J. McGill, 2007: Initial performance assessment of CALIOP. Geophys. Res. Lett., 34, L19803, https://doi.org/10.1029/2007GL030135.

Yanai, M., S. Esbensen, and J.-H. Chu, 1973: Determination of bulk properties of tropical cloud clusters from large-scale heat and moisture budgets. J. Atmos. Sci., 30, 611-627, https://doi.org/10.1175/1520-0469(1973)030<0611:DOBPOT $>2.0$. $\mathrm{CO} ; 2$.

Yuan, J., and R. A. Houze, 2010: Global variability of mesoscale convective system anvil structure from A-train satellite data. J. Climate, 23, 5864-5888, https://doi.org/10.1175/2010JCLI3671.1. 